\title{
Assessing Sea-State Effects on Sea-Salt Aerosol Modeling in the Lower Atmosphere Using Lidar and In-Situ Measurements
}

\author{
George Varlas ${ }^{1, *(\mathbb{D})}$, Eleni Marinou ${ }^{2,3}{ }^{(0)}$, Anna Gialitaki ${ }^{2}$, Nikolaos Siomos ${ }^{2}$, Konstantinos Tsarpalis 4 , \\ Nikolaos Kalivitis ${ }^{2,5}$, Stavros Solomos ${ }^{6}$, Alexandra Tsekeri ${ }^{2}$, Christos Spyrou ${ }^{2}{ }^{2}$, Maria Tsichla ${ }^{2}$, \\ Anna Kampouri ${ }^{2}{ }^{\mathbb{D}}$, Vassilis Vervatis ${ }^{7}{ }^{-}$, Elina Giannakaki ${ }^{7}$, Vassilis Amiridis ${ }^{2}$, Nikolaos Mihalopoulos ${ }^{5,8}{ }^{\circ}$, \\ Anastasios Papadopoulos ${ }^{1}(\mathbb{B})$ and Petros Katsafados ${ }^{4}(\mathbb{D}$
}

check for updates

Citation: Varlas, G.; Marinou, E.; Gialitaki, A.; Siomos, N.; Tsarpalis, K.; Kalivitis, N.; Solomos, S.; Tsekeri, A.; Spyrou, C.; Tsichla, M.; et al.

Assessing Sea-State Effects on Sea-Salt Aerosol Modeling in the Lower Atmosphere Using Lidar and In-Situ Measurements. Remote Sens. 2021, 13, 614. https://doi.org/10.3390/ rs13040614

Academic Editor: Camelia Talianu Received: 17 December 2020

Accepted: 3 February 2021

Published: 9 February 2021

Publisher's Note: MDPI stays neutral with regard to jurisdictional claims in published maps and institutional affiliations.

Copyright: (c) 2021 by the authors. Licensee MDPI, Basel, Switzerland. This article is an open access article distributed under the terms and conditions of the Creative Commons Attribution (CC BY) license (https:// creativecommons.org/licenses/by/ $4.0 /)$.
1 Institute of Marine Biological Resources and Inland Waters, Hellenic Centre for Marine Research, 19013 Anavyssos, Greece; tpapa@hcmr.gr

2 Institute for Astronomy, Astrophysics, Space Applications and Remote Sensing, National Observatory of Athens, 10560 Athens, Greece; elmarinou@noa.gr (E.M.); togialitaki@noa.gr (A.G.); nsiomos@noa.gr (N.S.); nkalivitis@noa.gr (N.K.); atsekeri@noa.gr (A.T.); cspyrou@noa.gr (C.S.); mtsichla@noa.gr (M.T.); akampouri@noa.gr (A.K.); vamoir@noa.gr (V.A.)

3 Institute of Atmospheric Physics, German Aerospace Center (DLR), Oberpfaffenhofen, 82234 Weßling, Germany

4 Department of Geography, Harokopio University of Athens, 17671 Athens, Greece; ktsarpalis@hua.gr (K.T.); pkatsaf@hua.gr (P.K.)

5 Environmental Chemical Processes Laboratory, Department of Chemistry, University of Crete, 70013 Heraklion, Greece; nmihalo@noa.gr

6 Research Centre for Atmospheric Physics and Climatology, Academy of Athens, 10680 Athens, Greece; ssolomos@academyofathens.gr

7 Department of Physics, National and Kapodistrian University of Athens, 15784 Athens, Greece; vervatis@oc.phys.uoa.gr (V.V.); elina@phys.uoa.gr (E.G.)

8 Institute for Environmental Research and Sustainable Development, National Observatory of Athens, 15236 Athens, Greece

* Correspondence: gvarlas@hcmr.gr; Tel.: +30-22910-76399

Abstract: Atmospheric-chemical coupled models usually parameterize sea-salt aerosol (SSA) emissions using whitecap fraction estimated considering only wind speed and ignoring sea state. This approach may introduce inaccuracies in SSA simulation. This study aims to assess the impact of sea state on SSA modeling, applying a new parameterization for whitecap fraction estimation based on wave age, calculated by the ratio between wave phase velocity and wind speed. To this end, the new parameterization was incorporated in the coupled Chemical Hydrological Atmospheric Ocean wave modeling System (CHAOS). CHAOS encompasses the wave model (WAM) two-way coupled through the OASIS3-MCT coupler with the Advanced Weather Research and Forecasting model coupled with Chemistry (WRF-ARW-Chem) and, thus, enabling the concurrent simulation of SSAs, wind speed and wave phase velocity. The simulation results were evaluated against in-situ and lidar measurements at 2 stations in Greece (Finokalia on 4 and 15 July 2014 and Antikythera-PANGEA on 15 September 2018). The results reveal significant differences between the parameterizations with the new one offering a more realistic representation of SSA levels in some layers of the lower atmosphere. This is attributed to the enhancement of the bubble-bursting mechanism representation with air-sea processes controlling whitecap fraction. Our findings also highlight the contribution of fresh wind-generated waves to SSA modeling.

Keywords: CHAOS modeling system; sea spray; whitecapping; lidar vertical profiles; air-sea interaction; atmosphere-wave-chemistry coupled models; liric algorithm

\section{Introduction}

Sea-salt aerosols (SSAs) are released from sea-spray droplets directly produced at the air-sea interface and constitute a major component of the natural aerosol mass. SSAs often 
dominate the marine aerosol concentrations, mainly in the absence of anthropogenic or other continental (e.g., mineral dust) aerosols [1]. SSAs primarily are formed due to the dynamic effect of the wind on the sea surface [2]. The SSAs production on a global scale has been estimated at approximately $0.3-30 \times 10^{12} \mathrm{~kg} \mathrm{yr}^{-1}$ which corresponds to a significant component of the total natural aerosol production [3].

There are two main mechanisms responsible for sea-spray droplets formation [3]. The first one is the air-bubble bursting during whitecapping which releases film and jet droplets. The wind-wave interaction leads to air bubbles entrapment beneath the sea surface. These air bubbles, due to their buoyancy, reach the sea surface bursting and forming droplets as a result of two processes [4]. In the first process, film caps shatter producing small droplets [5]. In the second process, as bubble cavity collapses, an upwards accelerating water jet forms and breaks up into droplets [5]. The second mechanism of sea-spray production is the direct tearing of spume droplets from the tops of breaking waves [6-8] which is more prominent during strong winds observed, for example, in Mediterranean tropical-like cyclones "medicanes" [9]. Depending on the temperature and the relative humidity of the air, sea-spray droplets evaporate as they enter a dryer environment finally forming SSAs which either circulate in the atmosphere or drop back to the sea surface [3,6]. The circulating SSAs, usually with radius ranging from $0.1 \mu \mathrm{m}$ to $20 \mu \mathrm{m}$, are finally deposited on Earth surface through gravitational settling (dry deposition) and precipitation (wet deposition).

SSAs impact radiation and clouds having strong effects on climate and weather whilst affecting human health after their inhalation (Figure 1). More specifically, SSAs have a significant impact on the radiation transfer processes mainly through scattering [10-13]. SSAs also act as efficient cloud condensation nuclei [2,14] and even as ice nuclei [15], altering the formation and the albedo of clouds $[16,17]$ and, thus, determining the intensity and the pattern of precipitation [16,18-20]. SSAs play a key role on the electrification of the atmosphere as they transfer electric charges obtained during whitecap bubble bursting [21]. Moreover, SSAs affect the air quality, especially at the coastal areas [22], since they interact with other chemical compounds forming aerosols with different properties [23-25]. SSAs also encompass organic and inorganic material [26-29] and even harmful compounds such as hydrocarbons and other pollutants [30,31].

During the last decades, the modeling of SSAs has attracted the interest of the scientific community. Recently, integrated atmospheric and chemical models were applied in several studies to holistically simulate the processes related to the SSA emission, circulation, deposition and interaction with radiation and clouds $[2,16,20]$. One of the major SSA modeling limitations is the estimation of the whitecap fraction. SSA emissions are usually estimated through whitecap fraction expressed solely as a function of wind speed [32] without considering ocean properties such as sea state, sea surface temperature (SST), sea salinity and so forth. Anguelova and Webster [33] summarized many wind-speeddependent whitecap fraction parameterizations based on measurements and empirical methods. Such parameterizations ignore parameters such as sea state, wave age, sea surface temperature, sea salinity and sea surface circulation, as well as the stability of the atmospheric and oceanic surface layers, potential factors that affect SSA production [3]. Such approaches may lead to biases of the simulated SSA concentrations when comparing against in-situ measurements [34]. In this context, several research groups have begun to enrich SSA emission estimation with ocean-related parameters either through more complete estimations of whitecap fraction [35-42] or through other approaches, for example, estimating Reynolds number dependent on significant wave height [43]. 


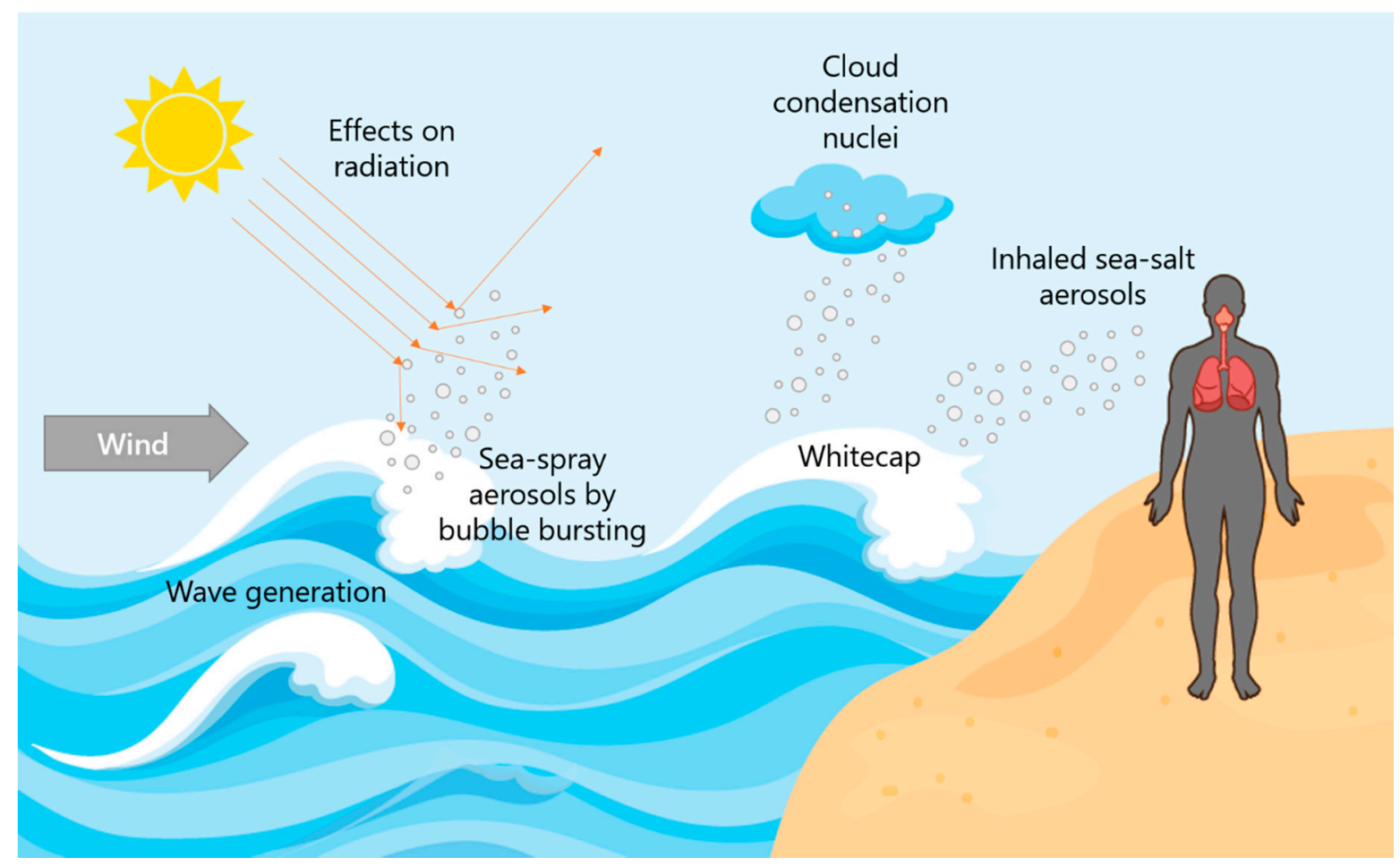

Figure 1. Schematic illustration of sea-spray production along the air-sea interface due to the interaction between the wind and the waves. Sea-spray releases salt particles affecting directly and indirectly the environment and the humans.

In this study, a sea-state-dependent parameterization for whitecap fraction estimation which was proposed by Laussac et al. [42] (L18 hereafter) and based on the initial work of Lafon et al. [38], was implemented in the SSA emission parameterization of the coupled Chemical Hydrological Atmospheric Ocean wave System (CHAOS) [44-49]. CHAOS encompasses the Advanced Weather Research and Forecasting (WRF-ARW) version 4.0 atmospheric model [50] including the WRF-Chem version 4.0 chemical model [51] and, two-way coupled with the version 4.5.4 wave model (WAM) [52-54] through the OASIS3MCT v3.0 coupler [55,56]. CHAOS also includes the WRF-Hydro hydrological model [57] which was not used in this study. The initial development of CHAOS was based on the experience of modeling the atmosphere-wave interaction processes [58] gained during the EU FP7 project "MyWave: A pan-European concerted and integrated approach to operational wave modelling and forecasting-a complement to GMES MyOcean services." The system was further expanded with additional air-sea parameterization schemes presented in the PhD dissertation of Varlas [44]. Recently, CHAOS was upgraded to a fully multi-way coupled system including the Nucleus for European Modelling of the Ocean NEMO [59] as ocean circulation component [49], however it has not yet been integrated in the sea-salt estimation process, so it was not used in this study. Thus, the advanced coupling capabilities of CHAOS and its integrated representation of atmosphere-wave processes facilitate the application of a sea-state-dependent SSA emission estimation. The SSA emission and circulation in CHAOS were simulated by the Goddard Chemistry Aerosol Radiation and Transport (GOCART) aerosol module [60,61] of the WRF-Chem model using the parameterization of Monahan et al. [62] and Gong et al. [63], focusing on the bubble-bursting mechanism. This parameterization is based on whitecap fraction roughly estimated as a function of the 10-m wind speed [32] (M80 hereafter), provided by the WRF-ARW model. M80 parameterization uses a power-law expression forcing the whitecap fraction to sharply increase with the wind speed, ignoring wave conditions. On the other hand, the newly implemented L18 parameterization is dependent on the wave age through the ratio between the wave phase velocity estimated by the WAM model and the wind speed estimated by the WRF-ARW model. Recent studies [64] showcased that compared with wind speed, 
the impact of wave age on whitecap fraction is more robust as it more completely represents air-sea processes under various wind regimes. To investigate the impact of sea state on whitecap fraction and, subsequently, on SSA levels in the lower atmosphere, CHAOS was set up to perform sensitivity simulations implementing the L18 and M80 parameterizations for three case studies in Greece. The simulation results were assessed using in-situ SSA concentration measurements and lidar-derived SSA concentrations at Finokalia station (Crete, Greece) on 4 and 15 July 2014 and at PANGEA observatory (Antikythera, Greece) on 15 September 2018.

This paper is organized as follows-the model setup, the in-situ measurements and the lidar-derived observations are presented in Section 2. Section 3 presents the results of this study comparing and physically interpreting the simulated SSA emissions and concentrations. Section 3 also presents the assessment of the simulated SSA concentrations in the lower atmosphere using the in-situ measurements and the lidar-derived observations during the three case studies. Section 4 presents a brief discussion and Section 5 summarizes the conclusions and indicates future directions of this study.

\section{Models and Instrumentations}

\subsection{Model Setup}

In this study, the L18 whitecap fraction parameterization dependent on both wind speed and sea state was implemented in the CHAOS modeling system and was compared with the wind-speed-dependent M80 parameterization already existing in the system, against in-situ and lidar measurements. Such an effort can be feasible using the integrated wave-atmosphere-chemistry modeling chain of CHAOS, which combines air-sea-aerosol processes "online" resulting to a more holistic representation of SSA emissions in the surface layer and, subsequently, of SSA concentrations in the boundary layer and even higher. Model setup of the atmospheric, ocean wave and chemical components of CHAOS as well as coupling design and implementation of integrated parameterizations of SSA production are described in the next subsections.

\subsubsection{Atmospheric Model Setup}

WRF-ARW model was set up on an Arakawa-C domain of $488 \times 242$ grid points covering the Mediterranean Sea with $10 \mathrm{~km} \times 10 \mathrm{~km}$ horizontal grid spacing (Figure 2). A 60-s time step and 38 terrain-following vertical levels stretching from the surface up to the isobaric level of $50 \mathrm{hPa}$ were used. Global Forecasting System operational analyses (GFS-ANL) from the National Centers for Environmental Prediction (NCEP) with $0.5^{\circ} \times 0.5^{\circ}$ horizontal grid spacing were used to construct the initial and boundary conditions (update every $6 \mathrm{~h}$ ). Real-time global (RTG) SST analyses from the NCEP with $0.083^{\circ} \times 0.083^{\circ}$ horizontal grid spacing were used to define the lower boundary conditions applying SST update every $6 \mathrm{~h}$. The topographic input data were based on the Global Multi-resolution Terrain Elevation Data 30-arcsec USGS GMTED 2010 [65]. The revised Monin-Obukhov scheme [66] was used to parameterize the processes in the surface layer, including several modifications to encapsulate sea-state conditions "online" estimated by WAM [45]. To represent the Planetary Boundary Layer (PBL) processes the Yonsei University scheme-YSU [67] was used. The ground processes were represented by the unified land surface model (Unified NOAH) [68]). To parameterize the longwave and shortwave radiation processes the RRTMG scheme [69] was used. The Thompson scheme [70] and the Grell and Freitas ensemble scheme [71] were used to represent the cloud microphysics and convective processes, respectively.

\subsubsection{Ocean Wave Model Setup}

WAM model was set up on a regular lat-lon domain covering the area $8^{\circ} \mathrm{W}-42^{\circ} \mathrm{E}$ and $29^{\circ} \mathrm{N}-48^{\circ} \mathrm{N}$ as shown in Figure 2 (purple line) using a horizontal grid spacing of $0.1^{\circ} \times 0.1^{\circ}$ with $501 \times 191$ grid points. Source and propagation time steps were set to $600 \mathrm{~s}$ and $75 \mathrm{~s}$, respectively. The wave spectra were discretized using 25 frequency bins (ranging 
from 0.042 to $0.411 \mathrm{~Hz}$ ) and 24 directional bins ( $15^{\circ}$ directional resolution). The initialization of the wave component was based on a "hot start" approach using initial wave spectrum based on the results of 6-day preprocessing simulations. In this way, WAM can more realistically represent wave generation and propagation as noted by Katsafados et al. [58] and Varlas et al. [45]. The bathymetric input data were made using the Etopo1 data (1-min Gridded Global Relief Data) [72].

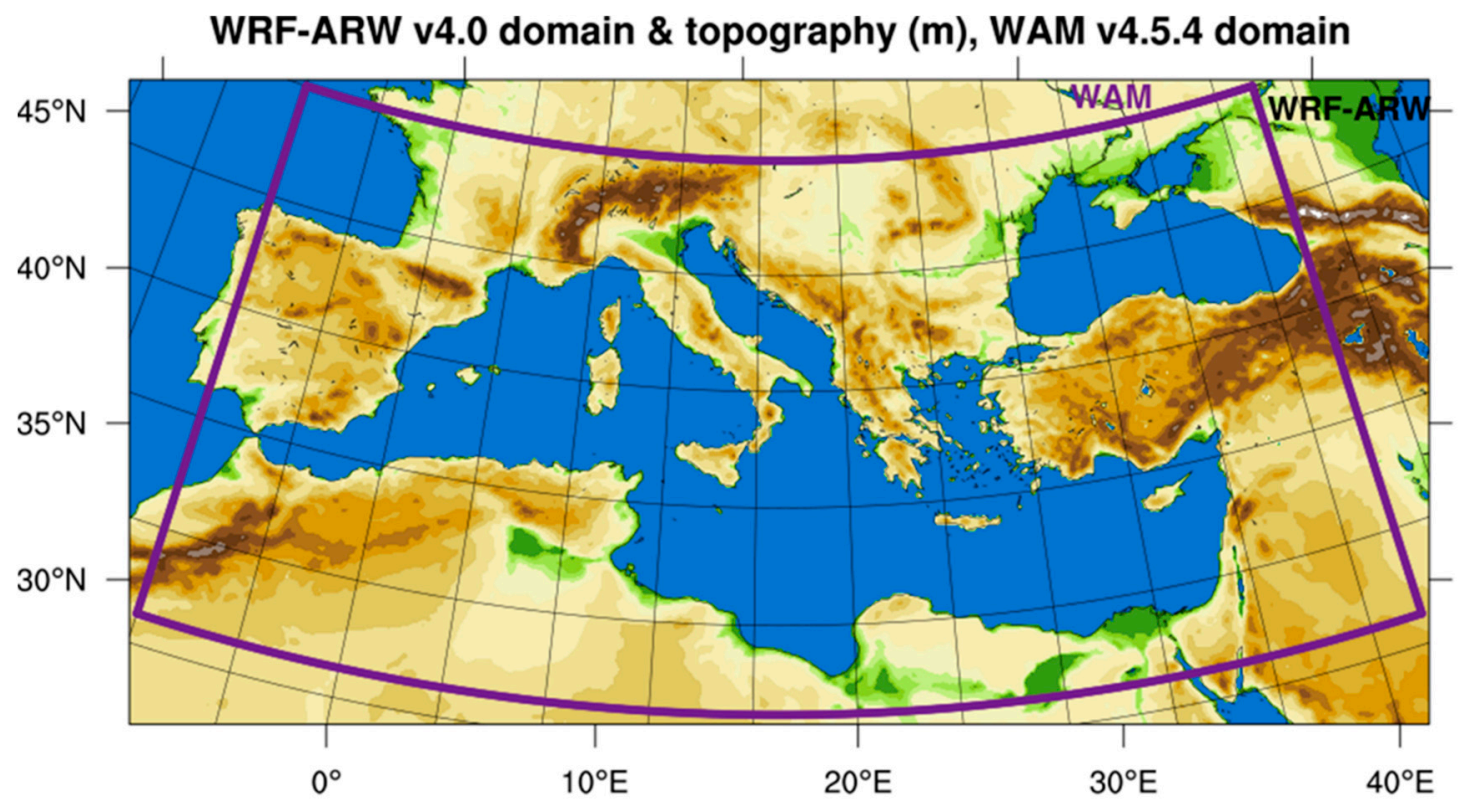

(a)
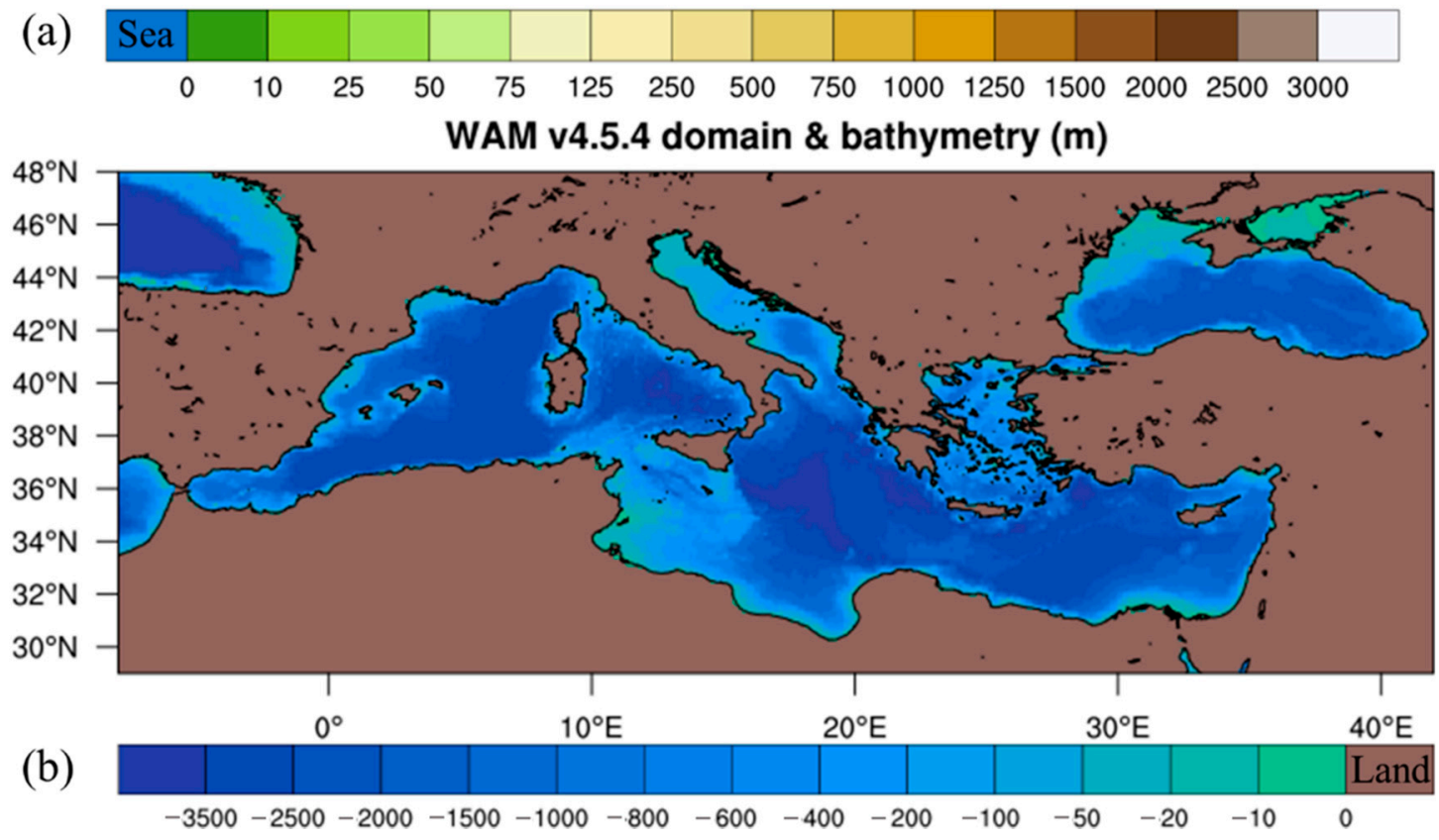

Figure 2. (a) Advanced Weather Research and Forecasting (WRF-ARW) model v4.0 and wave model (WAM) v4.5.4 (purple line) domains. Topography $(\mathrm{m})$ used by the WRF-ARW v4.0 model is also presented. WRF-Chem v4.0 model uses the same domain and topography as WRF-ARW v4.0 model; (b) WAM v4.5.4 model domain and bathymetry (m) used.

\subsubsection{Atmospheric-Wave Model Exchange Setup}

The WRF-ARW and WAM models were set to "online" exchange fields every $600 \mathrm{~s}$ (i.e., equal to the source time step of WAM) through OASIS3-MCT coupler. The sea-statedependent Charnock parameter $\alpha$ (dimensionless) and the wave phase velocity at the peak of the wave spectrum $C_{p}\left(\mathrm{~m} \mathrm{~s}^{-1}\right)$ estimated by WAM [44] were configured to be sent 
to WRF-ARW whilst $U_{10-m e r}$ and $U_{10-z o n}$ meridional and zonal components $\left(\mathrm{m} \mathrm{s}^{-1}\right)$ of 10-m wind, respectively, estimated by WRF-ARW were configured to be sent to WAM. The Charnock parameter was used in the estimation of roughness length (m) in WRF-ARW using Charnock's (1955) equation enriched by a viscous sublayer part [73]:

$$
z_{0}=\frac{a u_{*}^{2}}{g}+\frac{0.11 v}{u_{*}}
$$

where $g$ is the Earth's gravitational acceleration constant $\left(\mathrm{m} \mathrm{s}^{-2}\right), u_{*}$ is friction velocity $\left(\mathrm{m} \mathrm{s}^{-1}\right)$ and $v$ is air kinematic viscosity $\left(\mathrm{m}^{2} \mathrm{~s}^{-1}\right)$. The sea-state-dependent Charnock parameter estimation is based on the quasi-linear theory of wind-wave generation [74-76] and is given by

$$
\alpha=\frac{0.01}{\sqrt{1-\frac{\tau_{w}}{\tau}}}
$$

where $\tau_{w}$ is the wave stress $\left(\mathrm{N} \mathrm{m}^{-2}\right)$ and $\tau$ is the total stress $\left(\mathrm{N} \mathrm{m}^{-2}\right)$, that is, adding turbulent and wave stresses while neglecting viscous stress. The wave phase velocity at the peak of the wave spectrum is defined as follows:

$$
c_{p}=\sqrt{\frac{g \lambda_{p}}{2 \pi} \tanh \left(\frac{2 \pi h}{\lambda_{p}}\right)},
$$

where $\lambda_{p}$ is the wavelength (m) at the peak of the wave spectrum and $h$ is the water depth (m).

\begin{tabular}{|c|c|c|}
\hline Model Setup & WRF-ARW v4.0 & WAM v4.5.4 \\
\hline Horizontal grid spacing & $10 \mathrm{~km} \times 10 \mathrm{~km}$ & $0.1^{\circ} \times 0.1^{\circ}$ \\
\hline Time steps & $60 \mathrm{~s}$ & Source $600 \mathrm{~s}$, Propagation $75 \mathrm{~s}$ \\
\hline Vertical Levels & 38 & \\
\hline Initial \& Boundary Conditions & $\begin{array}{l}\text { GFS-ANL }\left(0.5^{\circ} \times 0.5^{\circ}\right), \text { RTG SST }\left(0.083^{\circ} \times 0.083^{\circ}\right) \\
\text { update \& sea-state-dependent Charnock }(\alpha)\end{array}$ & $\begin{array}{l}\text { "Hot start" through 6-day } \\
\text { pre-processing simulations }\end{array}$ \\
\hline Surface layer & $\begin{array}{l}\text { Revised Monin-Obukhov [66] modified by Varlas } \\
\text { et al. [45] }\end{array}$ & \\
\hline PBL & Yonsei University (YSU) [67] & \\
\hline Cloud microphysics & Thompson [70] & \\
\hline Cumulus & Grell-Freitas ensemble [71] & \\
\hline Land & Unified NOAH [68] & \\
\hline Radiation & RRTMG [69] & \\
\hline Topography/Bathymetry & GMTED 2010 [65] & ETOPO1 [72] \\
\hline Spectral resolution & & $\begin{array}{l}24 \text { directions \& } 25 \text { frequencies } \\
(0.042-0.411 \mathrm{~Hz})\end{array}$ \\
\hline Exchanged fields & \multicolumn{2}{|c|}{$U_{10-m e r} \& U_{10-z o n}\left(\right.$ WRF to WAM), $C_{p} \& \alpha$ (WAM to WRF) } \\
\hline Exchange frequency & \multicolumn{2}{|l|}{$600 \mathrm{~s}$} \\
\hline
\end{tabular}

Main model setup settings and exchange characteristics are summarized in Table 1.

Table 1. Configuration settings of WRF-ARW v4.0 and WAM v4.5.4 models.

2.1.4. SSA Emission Modeling and Implementation of L18 Whitecap Fraction Parameterization

The WRF-Chem model was set up on the same domain as the WRF-ARW model and used the Goddard Chemistry Aerosol Radiation and Transport (GOCART) aerosol 
module $[60,61]$ for SSA modeling. It is important to note here that no aerosol-to-atmosphere feedbacks were considered in this study facilitating a more straightforward comparison of the two parameterizations. SSA modeling is determined by SSA emissions $\left(\mu \mathrm{g} \mathrm{m}^{-2} \mathrm{~s}^{-1}\right)$ along the air-sea interface, estimated by approximating the dry sea-salt mass released during the sea-spray droplets production. In this study, the latter is represented by the empirical density function $\frac{d F_{0}}{d r}$ (particles $\mathrm{m}^{-2} \mathrm{~s}^{-1} \mu \mathrm{m}^{-1}$ ) proposed by Monahan et al. [62] and modified by Gong et al. [63]. It expresses the rate of sea-spray droplet generation per unit area of sea surface, per increment of particle radius $r$. It is dependent on the whitecap fraction $W$ (dimensionless), the time constant $\tau$ characterizing the whitecap decay, taken as $3.53 \mathrm{~s}$ [76] and the shape function $\frac{d E}{d r}$ that is, the number of droplets generated by bubblebursting processes during the gradual decay of a whitecap surface unit per increment droplet radius $\left(\mathrm{m}^{-2} \mu \mathrm{m}^{-1}\right)$. It is given by

$$
\frac{d F_{0}}{d r}=W \tau^{-1} \frac{d E}{d r}=W \times 3.53^{-1} \times 1.262 \times 10^{6} \times r^{-3}\left(1+0.057 r^{1.05}\right) \times 10^{1.19 e^{\left(-B^{2}\right)}}
$$

where $B=(0.38-\log r) / 0.65$.

To estimate whitecap fraction $W$, the GOCART aerosol module of the version 4.0 of WRF-Chem model uses by default the M80 [32] wind-speed-dependent parameterization with a small modification in the $10-\mathrm{m}$ wind speed $U_{10}\left(\mathrm{~m} \mathrm{~s}^{-1}\right)$ exponent that is, 3.2 instead of 3.41 of the original equation. Therefore, M80 whitecap fraction is given by

$$
W=3.84 \times 10^{-6} U_{10}^{3.2} .
$$

Using the M80 whitecap fraction, the density function used in the GOCART module is given by

$$
\frac{d F_{0}}{d r}=1.373 \times U_{10}^{3.2} r^{-3}\left(1+0.057 r^{1.05}\right) \times 10^{1.19 e^{\left(-B^{2}\right)}} .
$$

To assess sea-state effects on SSA emissions that determine SSA modeling in the atmosphere, the wave-age-dependent L18 parameterization for the whitecap fraction estimation proposed by Laussac et al. [42] was implemented in the density function (Equation (4)) in the GOCART module modifying several modules of CHAOS components. It is important to note here that the simulations were suitably designed to differ only on whitecap fraction parameterization used following M80 and L18 approaches. The L18 parameterization was developed using measurements at the northwestern Mediterranean Sea and it was based on the work of Lafon et al. [38] that aimed to incorporate fetch and wave age information in the whitecap fraction estimation. L18 parameterization consists of two parts according to the range of wave age (dimensionless) values estimated by the ratio between the wave phase velocity ( $C_{p}$ was used in this study) and the $10-\mathrm{m}$ wind speed $U_{10}$. L18 parameterization is thus given by

$$
\begin{gathered}
W(\%)=20\left(C_{p} / U_{10}\right)^{2.5} \\
W(\%)=0.6\left(C_{p} / U_{10}\right)^{-0.41}
\end{gathered}
$$

for $C_{p} / U_{10} \leq 0.35, C_{p} / U_{10}>0.35$.

Wave phase velocity at the peak of the spectrum (Equation (3)) as estimated by WAM model [44] was used for $C_{p}$ in this study, as more suitable to represent the propagation of wave crests. The exponents 2.5 and -0.41 are related with active whitecaps after initial wave breaking whilst the constants 20 and 0.6 are related with passive whitecaps during decay phase of breaking waves. The density function was modified accounting that L18 whitecap fraction is expressed in (\%). Therefore, the modified density function using L18 whitecap fraction is given by

$$
\begin{gathered}
\frac{d F_{0}}{d r}=7.151 \times 10^{4} \times\left(C_{p} / U_{10}\right)^{2.5} r^{-3}\left(1+0.057 r^{1.05}\right) \times 10^{1.19 e^{\left(-B^{2}\right)}} \\
\frac{d F_{0}}{d r}=0.215 \times 10^{4} \times\left(C_{p} / U_{10}\right)^{-0.41} r^{-3}\left(1+0.057 r^{1.05}\right) \times 10^{1.19 e^{\left(-B^{2}\right)}}
\end{gathered}
$$


for $C_{p} / U_{10} \leq 0.35, C_{p} / U_{10}>0.35$.

The transport sea-salt size distribution in the model using either M80 or L18 whitecap fraction is represented with four radius bins. These four bins correspond to the following radius ranges: $\operatorname{bin} 1(\mathrm{r}=0.1-0.5 \mu \mathrm{m})$, bin $2(\mathrm{r}=0.5-1.5 \mu \mathrm{m})$, bin $3(\mathrm{r}=1.5-5 \mu \mathrm{m})$ and bin4 $(\mathrm{r}=5-10 \mu \mathrm{m})$ following Chin et al. [61]. It is noteworthy that the application of density function for the radius ranges of bins facilitates a more detailed discretization of SSAs, compared to an alternative approach without the use of bins. The transport size distribution is based on the dry radius of the particles and it is used for describing the SSA transport in the GOCART aerosol module of the WRF-ARW-Chem model. However, the source SSA size distribution that is used in the density function is estimated considering $80 \% \mathrm{RH}$ (instead of dry particles) in order to represent the ambient moisture conditions along the air-sea interface. For that reason, the radii of the four bins in the density function calculations for SSA flux are considered to be doubled according to Chin et al. [61]; de Leeuw et al. [1]. Hence, at $80 \%$ RH the four model bins are assumed to represent the following radius ranges: bin $1(\mathrm{r}=0.2-1 \mu \mathrm{m})$, bin2 (for $\mathrm{r}=1-3 \mu \mathrm{m})$, bin3 $(\mathrm{r}=3-10 \mu \mathrm{m})$ and bin $4(\mathrm{r}=10-20 \mu \mathrm{m})$. As marked by de Leeuw et al. [1], such a size extension (i.e., bin4 with $r=10-20 \mu \mathrm{m}$ at $80 \%$ $\mathrm{RH}$ ) is out of the validity range of the density function proposed by Monahan et al. [62] which is valid for $r=0.2-10 \mu \mathrm{m}$ at $80 \%$ RH [42] and, thus, only the first 3 bins are considered for this study.

In this context, the calculation of the sea-spray number flux along the air-sea interface is initially performed considering the source radii at $80 \% \mathrm{RH}$ but afterwards the SSA mass in the model is redistributed in the dry transport bins ignoring the water content of droplets. Therefore, the dry SSA mass concentration in each of the first 3 bins considered in this study is estimated for each grid cell considering the dry sea-salt density $\left(2200 \mathrm{~kg} \mathrm{~m}^{-3}\right)$ and the equivalent dry sea-salt volume, assuming that dry radius is a half of radius at $80 \%$ RH [1,61].

It is important to note here that all SSA simulations were based on initial SSA concentrations produced by 6-day preprocessing simulations adopting a "hot start" approach as also applied for the wave modeling. In this way, WRF-Chem was initialized with non-zero SSA concentrations in the lower atmosphere that is considered as more realistic than a "cold start" approach that delays the vertical transport of SSAs.

Figure 3 illustrates CHAOS chain procedures for SSA modeling according to the methodology presented. The results were assessed in three case studies using in-situ measurements and lidar-derived observations as presented in the following sections.

\subsection{Lidar Observations and In-Situ Measurements Over Eastern Mediterranean}

The implementation of the new whitecap fraction parameterization in CHAOS was assessed using observations collected during the CHARADMExp campaign (CHARacterization of Aerosol mixtures of Dust and Marine origin Experiment; http:/ / charadmexp.gr (accessed on 17 December 2020); June-July 2014) and in the frame of the ERC D-TECT grant (Does dust triboelectrification affect our climate?; http:/ / d-tect.space.noa.gr/ (accessed on 17 December 2020); September 2018) over the Eastern Mediterranean. CHARADMExp took place at Finokalia station $\left(35.34^{\circ} \mathrm{N}, 25.67^{\circ} \mathrm{E}, 258 \mathrm{~m}\right.$ elevation, Greece http: / / finokalia.chemistry.uoc.gr/ (accessed on 17 December 2020)), located in the northeast part of the island of Crete. ERC D-TECT observations took place at the PANhellenic GEophysical observatory of Antikythera (PANGEA observatory; $35.86^{\circ} \mathrm{N}, 23.31^{\circ} \mathrm{E}, 193 \mathrm{~m}$ elevation, Greece, https:/ / react.space.noa.gr/ (accessed on 17 December 2020)). Both islandic stations are background stations of the Aerosol, Clouds and Trace Gases Research Infrastructure (ACTRIS, https: / /www.actris.eu/ (accessed on 17 December 2020)) and are representative of the marine conditions of Eastern Mediterranean [77,78].

Both campaigns were implemented by the National Observatory of Athens (NOA) with main objectives to characterize dust and marine particles, as well as to assess the impact of particle electrification on desert dust dynamics and long-range transport. Finokalia and Antikythera locations are both seaside stations far away from city centers and for 
that reason, they are ideal for studying the properties of aerosol particles originating from natural sources, like sea salt, under typical Mediterranean background conditions. In both campaigns, continuous lidar observations were collected along with in-situ measurements.

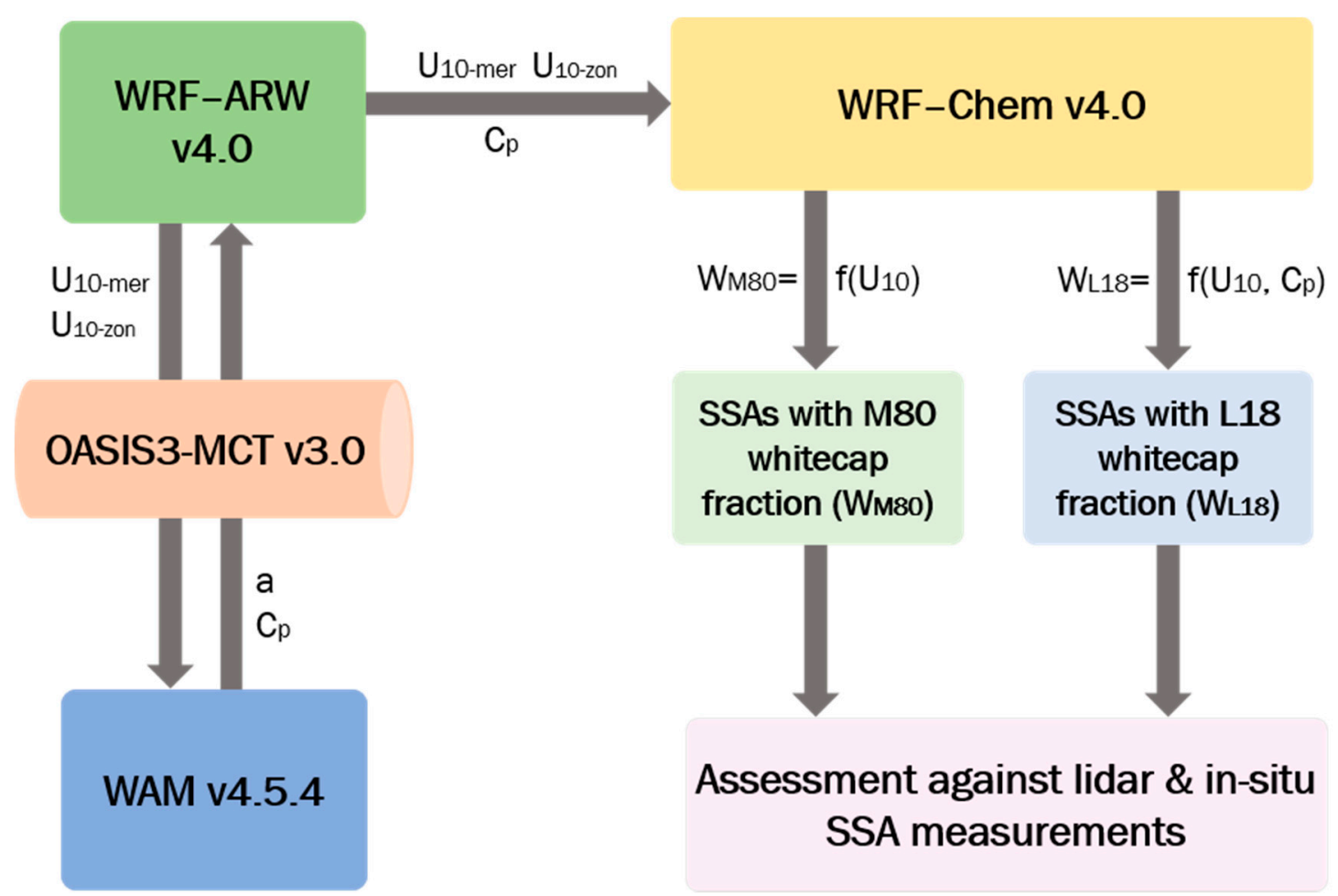

Figure 3. Schematic illustration of sea-salt aerosol (SSA) modeling by the WRF-Chem v4.0 chemical model using the M80 and L18 whitecap fraction parameterizations. The $U_{10-\text { mer }}$ and $U_{10-z o n}$ meridional and zonal components of $10-\mathrm{m}$ wind, respectively, estimated by the WRF-ARW v4.0 atmospheric model as well as the wave phase velocity at the peak of the wave spectrum $\left(C_{p}\right)$ and the Charnock parameter $(\alpha)$ estimated by the WAM v4.5.4 wave model are exchanged between the two models through the OASIS3-MCT v3.0 coupler. Consequently, $C_{p}, U_{10-\text { mer }}$ and $U_{10-z o n}$ are sent to WRF-Chem to estimate SSA emissions following M80 and L18 whitecap fraction parameterizations ( $\mathrm{W}_{\mathrm{M} 80}$ and $\mathrm{W}_{\mathrm{L} 18}$, respectively), based on 10-m wind speed $\left(U_{10}\right)$ for M80 and on the ratio between $C_{p}$ and 10-m wind speed $\left(U_{10}\right)$ for L18. SSA concentrations in the lower atmosphere simulated by WRF-Chem according to M80 and L18 SSA emissions were finally assessed using lidar-derived observations and in-situ measurements.

\subsubsection{Lidar Observations and Concentrations}

Two Polly ${ }^{\mathrm{XT}}$ lidar systems were deployed at Finokalia and Antikythera during the aforementioned campaigns, the Polly ${ }^{\mathrm{XT}}$-OCEANET and the Polly ${ }^{\mathrm{XT}}$-NOA systems [79]. Both systems are multi-wavelength lidar system with continuous, unattended operation capability and they are members of the European Aerosol Research Lidar Network (EARLINET; earlinet.org) [80] and the Raman and Polarization lidar NETwork (PollyNET; polly.tropos.de) [81]. Polly ${ }^{\mathrm{XT}}$ lidar systems enable the retrieval of the particle backscatter coefficient at 355, 532 and $1064 \mathrm{~nm}$ [82-85], the extinction coefficient at 355 and $532 \mathrm{~nm}$ [86], the depolarization ratio at 355 and $532 \mathrm{~nm}$ [87] and the water vapor mixing ratio at $407 \mathrm{~nm}$ [88]. The combined use of two receivers deployed by the system, a near and a far-range telescope, enables the retrieval of aerosol optical properties from the upper troposphere down to complex boundary layer structures. Specifically, they retrieve aerosol optical properties at height as low as $200 \mathrm{~m}$ above the ground (full overlap height of Polly ${ }^{\mathrm{XT}}$ lidars). The aforementioned observations can provide input data for inversion algorithms to obtain particle microphysical properties, such as the size distribution and concentration profiles. Well-known methodologies in the field take advantage not only from lidar 
measurements but also from coincident sun-photometer observations. This synergistic approach enhances the retrieval and delivers more accurate aerosol properties.

One such example is the LIRIC algorithm (LIdar-Radiometer Inversion Code) [89], used in this work, in order to calculate the SSA mass concentration profiles from lidar measurements taking also into account columnar microphysical properties provided by a collocated sun-photometer. The algorithm performs best for the separation of marine aerosols, that mainly reside in the coarse mode (coarse spherical particles) from aerosol mixtures, where particles of anthropogenic origin (fine spherical particles) and dust particles (non-spherical particles) co-exist [90]. An overview of the analysis scheme used in LIRIC is presented in Figure 4, followed by a short description.

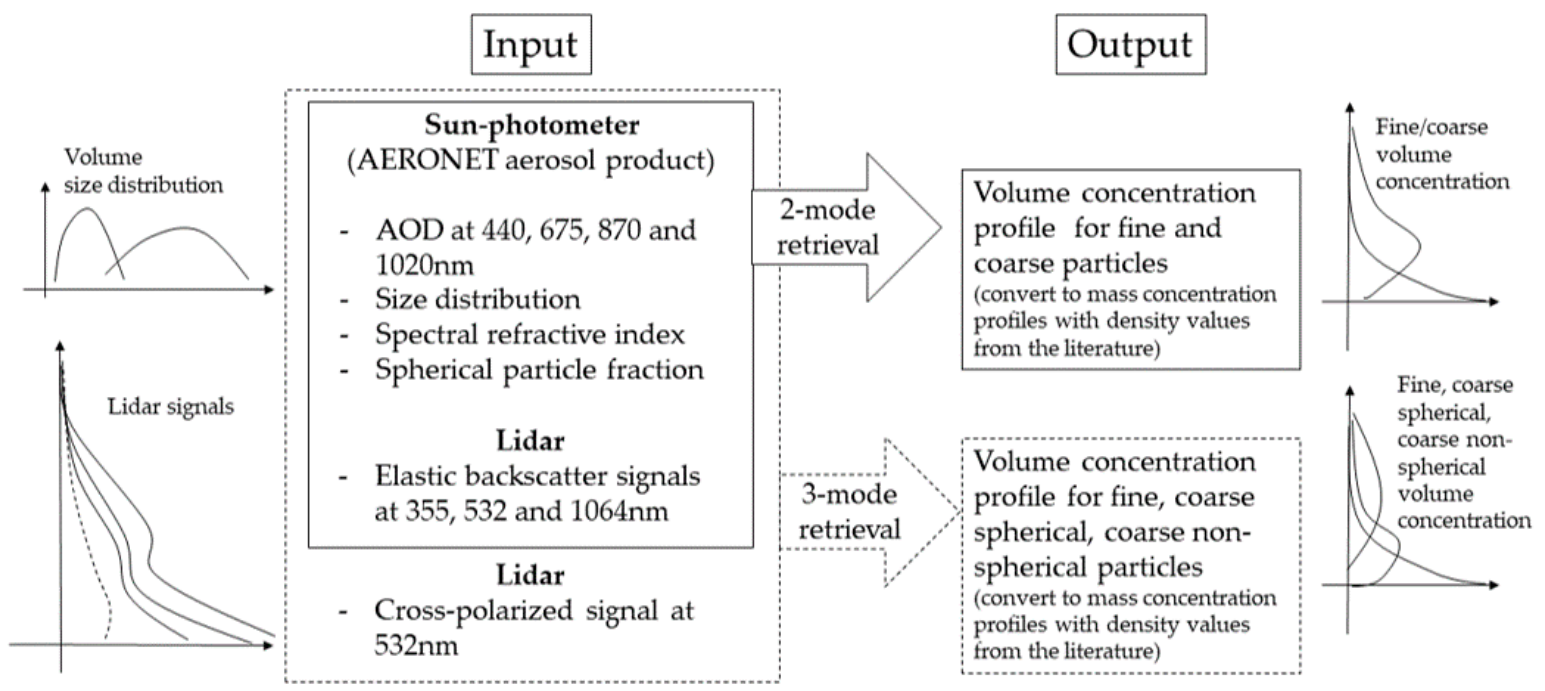

Figure 4. LIdar-Radiometer Inversion Code (LIRIC) Input and Output Parameters.

The LIRIC algorithm utilizes the synergy between lidar measurements and the AERONET aerosol product from the sun-photometer measurements and obtains vertically resolved particle concentrations. Specifically, the inputs are the total attenuated elastic backscatter signals at three lidar wavelengths $(355,532$ and $1064 \mathrm{~nm})$ and, optionally, the linearly cross polarized attenuated backscattered at $532 \mathrm{~nm}$, along with the columnar aerosol properties from the AERONET aerosol product such as the spectral Single Scattering Albedo, the aerosol volume size distribution and the spectral aerosol phase function. An optimal estimation algorithm identifies the vertical volume concentration profiles of atmospheric particles in up to three modes that best reproduce the measured lidar signals, considering the microphysical properties from the AERONET aerosol product. In the 2modes retrieval fine and coarse aerosols are separated. The 3-modes inversion is only available when the cross polarized attenuated backscatter at $532 \mathrm{~nm}$ is provided as input. In this case, fine, coarse spherical and coarse non-spherical aerosols are separated. The separation radius between fine and coarse modes is defined in LIRIC as the radius that corresponds to the AERONET size distribution minimum in the region 0.194-0.576 $\mu \mathrm{m}$. The algorithm is extensively described in Chaikovksy et al. [89]. It has already been validated using groundbased [90] and airborne [91] in-situ measurements and has also been inter-compared with the retrievals of similar aerosol inversion algorithms [90]. It has been applied in the past for the validation of desert dust transportation models [92] and air quality models [93].

At heights lower than the Polly ${ }^{\mathrm{XT}}$ full overlap (200 m above station), the volume concentration profiles of LIRIC algorithm are considered constant, which in case studies as those presented herein for marine particles, can introduce uncertainties to the lowermost part of the profile [94,95]. Furthermore, the coarse spherical volume concentration profiles of LIRIC (ppb) are assumed to solely correspond to the coarse sea salt particles. Some adaptations are required here as the definition of the coarse mode is different between CHAOS, 
LIRIC and the in-situ instruments. The bin 1 of the model at $80 \% \mathrm{RH}$ includes radii between 0.2 and $1.0 \mu \mathrm{m}$ and already contains part of the LIRIC coarse particles. The separation radius that corresponds to the lower boundary of the coarse mode in LIRIC is $0.439 \mu \mathrm{m}$ for all the cases in this study. In addition, the upper boundary of the coarse mode of LIRIC is $15 \mu \mathrm{m}$, in accordance with the AERONET inversions, while the bin3 of CHAOS ends at $10 \mu \mathrm{m}$. In order to make the LIRIC concentration profiles compatible with the model, the AERONET size distribution is deployed per case. LIRIC assumes constant shapes of the fine and coarse modes per vertical level. The coarse spherical and coarse non-spherical modes share the same shape. A common conversion approach is to integrate over the common size region of LIRIC and CHAOS $(0.439-10 \mu \mathrm{m})$ or LIRIC and in-situ $(0.439-5 \mu \mathrm{m})$ and calculate the fraction of the common to the total coarse mode concentration $(0.439-15 \mu \mathrm{m})$ with the AERONET size distribution. Then, this fraction is applied to convert the total coarse spherical particles of LIRIC to the model compatible SSAs per case. Details of this procedure can be found in, for example, Tsekeri et al. [90] and Siomos et al. [93]. The region $0.2-0.439 \mu \mathrm{m}$ that is included in the model is out of the coarse mode range of LIRIC where no separation of spherical particles and, consequently, of SSAs is possible. We have seen, however that the concentration fraction of this region to the total coarse mode of LIRIC is less than $0.2 \%$ in all the cases and probably even smaller considering that fine SSAs are only a fraction of the fine mode. This is expected since this region falls in the size distribution minimum. As a result, we assume that the lower boundaries of LIRIC and CHAOS are compatible and no further boundary corrections have to take place.

Another adaptation that is required here is to convert the volume sea salt concentration profiles of LIRIC (ppm) measured in ambient conditions to dry sea salt mass concentration profiles that are modeled in CHAOS $\left(\mu \mathrm{g} \mathrm{m}^{-3}\right)$. The conversion can be obtained when combining the definition of density with an empiric relationship of de Leeuw et al. [1], used to model the aerosol hygroscopic growth in regions where the relative humidity is sufficiently low, as follows

$$
m_{d r y}=\frac{d_{d r y} V_{a m b}}{1.26\left(1+\frac{1}{1-h}\right)} .
$$

Here, $m_{d r y}$ is the dry mass concentration, $h$ is the fractional relative humidity (RH) equal to $\mathrm{RH}(\%) / 100, d_{d r y}$ is the density of dry sea-salt particles $\left(2200 \mathrm{~kg} \mathrm{~m}^{-3}\right)$ and $V_{a m b}$ is the volume concentration estimated by LIRIC expressed in ppb. The relative humidity was estimated by the simulated profiles at Finokalia and Antikythera. Equation (9) was applied for the conversion in this study.

\subsubsection{In-Situ Measurements}

At Finokalia, aerosol PM10 samples were collected with a low volume sequential sampler (Comde-Derenda Gmbh) operated at $16.7 \mathrm{lpm}$ flowrate. Samples were collected on quartz fiber filters (Pallflex Membrane Filters Tissuquartz 2500qat-Up, $47 \mathrm{~mm}$ ). At PANGEA, samples were collected without a specific cut-off (corresponding thus to Total Suspended Particles; TSP) on pre-baked $8 \times 10$ in. quartz filters (2500QAT-UP, Pall) using a high-volume sampler for $24 \mathrm{~h}$ at a flow rate of $2 \mathrm{~m}^{3} \mathrm{~min}^{-1}$. Immediately after collection, the filter samples were wrapped in prebaked aluminum foil and refrigerated until analysis.

For the chemical analysis of the collected samples, $2 \mathrm{~cm}^{2}$ punches from the quartz filters were extracted in an ultrasonic bath and were then filtered using syringe filters to remove insoluble species. The acquired solutions were analyzed by ion chromatography for the determination of the main ionic species concentrations. Ions were determined using a Dionex-500 ion chromatograph equipped with an Ion Pac AS4A-SC column and an AG4ASC precolumn, with an ASRS-300 suppressor for anions determination, while cations, an Ion Pac CS12A column and a CG12A guard column were used [96]. Sea salt concentration was calculated based on aerosol ionic composition according to [97], so that [Sea salt] $=[\mathrm{Na}+]+$ $[\mathrm{Cl}-]+[\mathrm{ss}-\mathrm{Mg} 2+]+[\mathrm{ss}-\mathrm{K}+]+[\mathrm{ss}-\mathrm{Ca} 2+]+[\mathrm{ss}-\mathrm{SO} 2-4]$ (ss denotes the fraction of the specific ionic concentration with marine origin). 


\section{Results}

\subsection{Synoptic Analysis of the Three Case Studies}

The implementation of the new whitecap fraction parameterization in CHAOS was tested on three cases studies: 4 July 2014, 15 July 2014 and 15 September 2018. CHAOS was set up to simulate the three cases initializing on 3 July at 00:00 UTC, on 14 July 2014 at 00:00 UTC and on 13 September 2018 at 00:00 UTC, respectively. All the simulations were based on initial wave spectrum and SSA concentrations produced by 6-day preprocessing simulations. Figure 5a,c,e illustrates the mean sea level (MSL) pressure (color-shaded in $\mathrm{hPa}$ ) and the geopotential height (solid black contours in gpm) at $500 \mathrm{hPa}$ as well as Figure $5 \mathrm{~b}, \mathrm{~d}, \mathrm{f}$ demonstrates the temperature (color-shaded in ${ }^{\circ} \mathrm{C}$ ) at $500 \mathrm{hPa}$ for the three case studies, respectively, based on GFS-ANL data. The first case (4 July 2014) was characterized by "Etesian" winds, intense north-northeast winds over the Aegean Sea, as evidenced by the MSL pressure gradient between the high pressures over the Balkan Peninsula and the low pressures over Turkey and Cyprus. The second case (15 July 2014) was characterized by westerly winds over the southern Aegean Sea with lower intensity whilst an upper-air trough covered a wide region of Greece. The third case (15 September 2018) is a typical example of mild autumn weather with low atmospheric pressure gradients and low-moderate winds originated by various directions. Summarizing, the three cases can be considered to represent a wide range of wind conditions over the Aegean Sea, that is, the area where Finokalia and Antikythera stations are located, with high, moderate and low winds, respectively. This facilitates a good testing of the response of SSA emissions and concentrations on the different approaches for whitecap fraction estimation adopted in this study. Moreover, no cloudiness was observed according to satellite data (not shown) provided by the European Organization for the Exploitation of Meteorological Satellites (EUMETSAT) and online illustrated in https:/ / weather.us/satellite/greece/satellite-visible-archive/ (accessed on 17 December 2020). Subsequently, no rain was observed during the aerosol measurements at Finokalia and Antikythera stations as indicatively shown by the observations of the nearest meteorological stations of the National Observatory of Athens at Agios Nikolaos $\left(35.19^{\circ} \mathrm{N}, 25.72^{\circ}\right.$ E, 30 m elevation, Greece, http:/ / meteosearch.meteo.gr/data/aghiosnikolaos/2014-07.txt (accessed on 17 December 2020)) and at Falasarna (35.49 ${ }^{\circ}$ N, 23.58 E, $10 \mathrm{~m}$ elevation, Greece, http:/ / meteosearch.meteo.gr/data/falasarna/2018-09.txt (accessed on 17 December 2020)), respectively. The lack of rain during the aerosol measurements implies no wet deposition of SSAs, facilitating a more straightforward evaluation of the results against the measurements.

\subsection{Identification of Observed Aerosols and Air Masses}

On 4 July 2014, Polly ${ }^{\mathrm{XT}}$ measurements are presented in Figure 6. Daily variations of the aerosol load as well as the differences in the nature of the particles present above the station, are depicted in terms of the Total Attenuated Backscatter Coefficient at $1064 \mathrm{~nm}$ (Figure 6a) and the Volume Linear Depolarization Ratio at $532 \mathrm{~nm}$ (Figure 6b). These two quantities are indicative of the particles' concentration and shape respectively. To derive the optical and geometrical aerosol properties, needed for particle characterization, lidar measurements on this day were averaged between 04:00 and 06:00 UTC. Results are presented in Figure 6a as the particle backscatter coefficient profiles ( $\beta$; at 355, 532 and $1064 \mathrm{~nm}$ ) and in Figure $6 \mathrm{~b}$ (right) as particle depolarization ratio profiles $\left(\delta_{p} ;\right.$ at $\left.532 \mathrm{~nm}\right)$. In these lidar retrievals, the $\beta$ and $\delta_{p}$ present values characteristic of dust aerosols (found between 2 and $6 \mathrm{~km}$ ) and aerosols of marine origin (found below $1 \mathrm{~km}$ ).

For the characterization of the examined aerosol layers at Finokalia and Antikythera station the atmospheric dispersion FLEXPART-WRF model was used in backward mode for the computation of source-receptor relationships [98]. The dispersion model was coupled offline with the WRF-ARW atmospheric model. The backward FLEXPART runs were performed for 5-day periods and we assumed a release of 40,000 tracer particles from each layer that was observed at specific heights over Finokalia and Antikythera station. During this time interval, there was a mixture of marine, dust and continental particles present at Finokalia station. We created emission sensitivity maps with the information on the areas 
the tracer particles detected at heights between $0-1 \mathrm{~km}$ in the past 5-days, along with the information of the time that the tracer particles spend there. For this case study, the airmasses at lower altitudes (below $3 \mathrm{~km}$ ) follow north-northwestern directions (Figure $6 \mathrm{c}$; left and middle plot), carrying marine particles mostly from the Aegean Sea along with possible contribution of continental particles from the Balkans up to $1 \mathrm{~km}$ and a mixture of marine, continental and dust particles at 1-3 km. Between 2 and $6 \mathrm{~km}$ the air masses are related with in dust transport from the Sahara Desert (Figure 9a; right plot). The elevated dust plume was located between 3 and $6 \mathrm{~km}$ presenting $\delta_{p}$ values $22 \pm \%$, while the layer of interest consisting of marine and polluted continental particles originating from Northern Italy and the Balkans, is less depolarizing ( $\delta_{p}=4.3 \pm 0.4 \%$ ) and extends from the surface up to $2.5 \mathrm{~km}$.
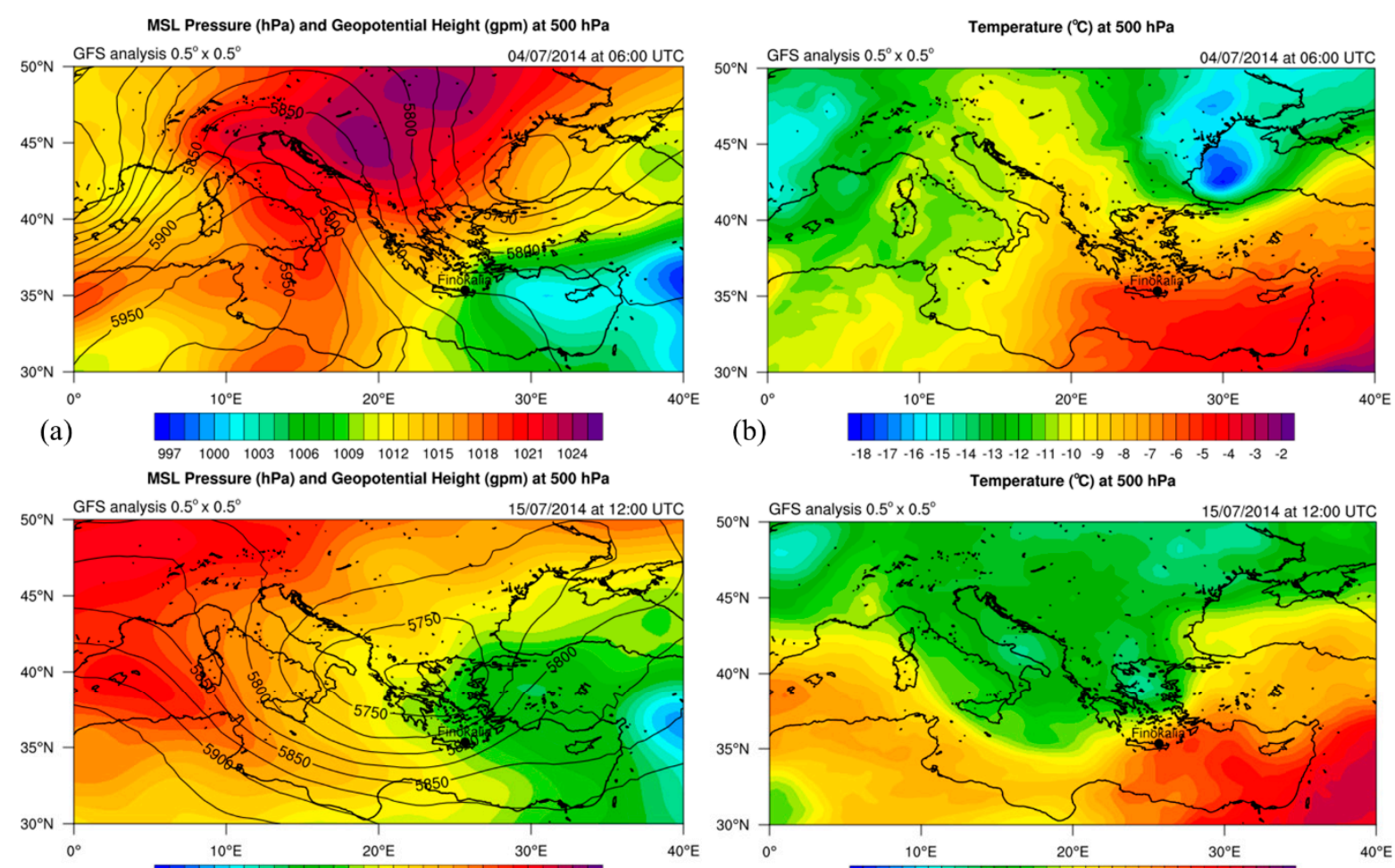

(c) $\quad$\begin{tabular}{llll|l|l|l|l|l|l|l|l|l|l|l}
997 & 1000 & 1003 & 1006 & 1009 & 1012 & 1015 & 1018 & 1021 & 1024
\end{tabular}
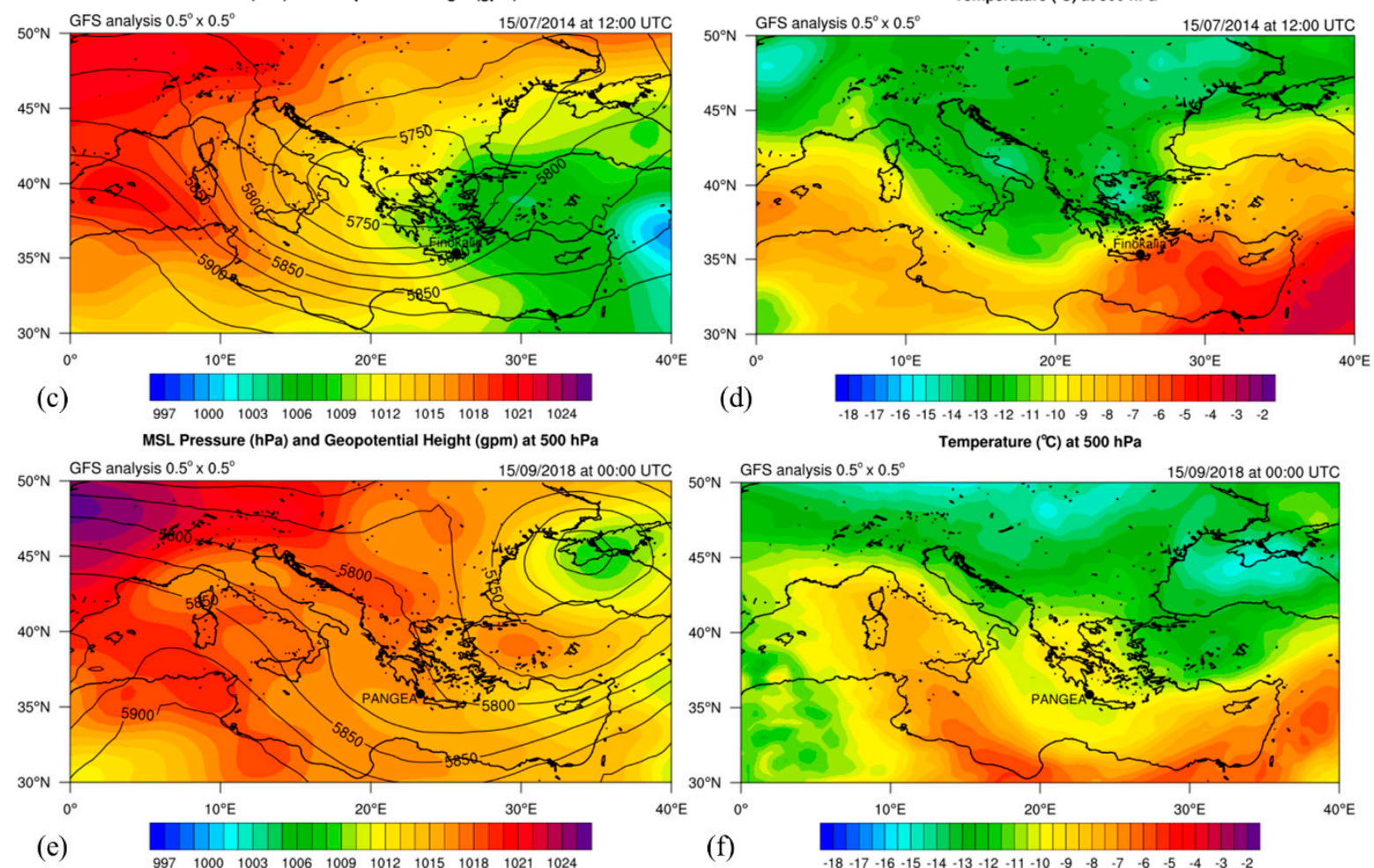

$-18-17-16-15-14-13-12-11-10-9-8 \quad-7$
Temperature $\left({ }^{\circ} \mathrm{C}\right)$ at $500 \mathrm{hPa}$

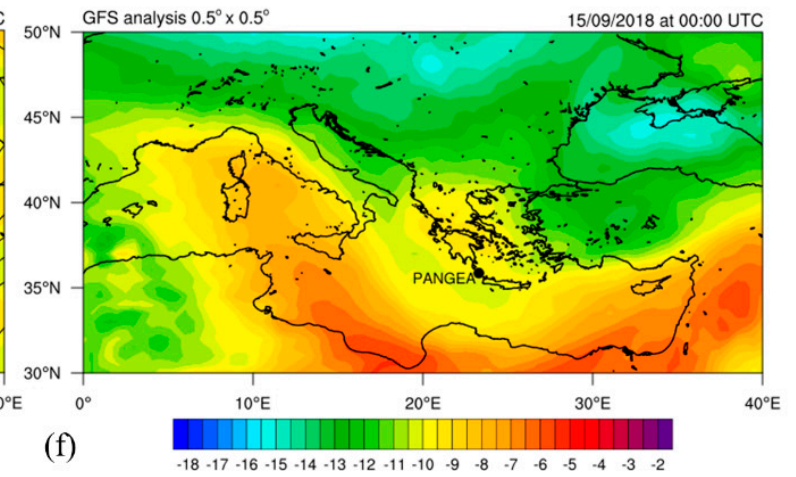

Figure 5. (a) Mean sea level (MSL) pressure (color-shaded in $\mathrm{hPa}$ ) and geopotential height (solid black contours in gpm) at $500 \mathrm{hPa}$ as well as (b) temperature (color-shaded in ${ }^{\circ} \mathrm{C}$ ) at $500 \mathrm{hPa}$ for 4 July 2014 at 06:00 UTC. Similarly for 15 July 2014 at 12:00 UTC (c,d) and 15 September 2018 at 00:00 UTC (e,f). The maps were based on Global Forecasting System operational analyses (GFS-ANL) data. PANGEA and Finokalia locations are also illustrated on the maps. 

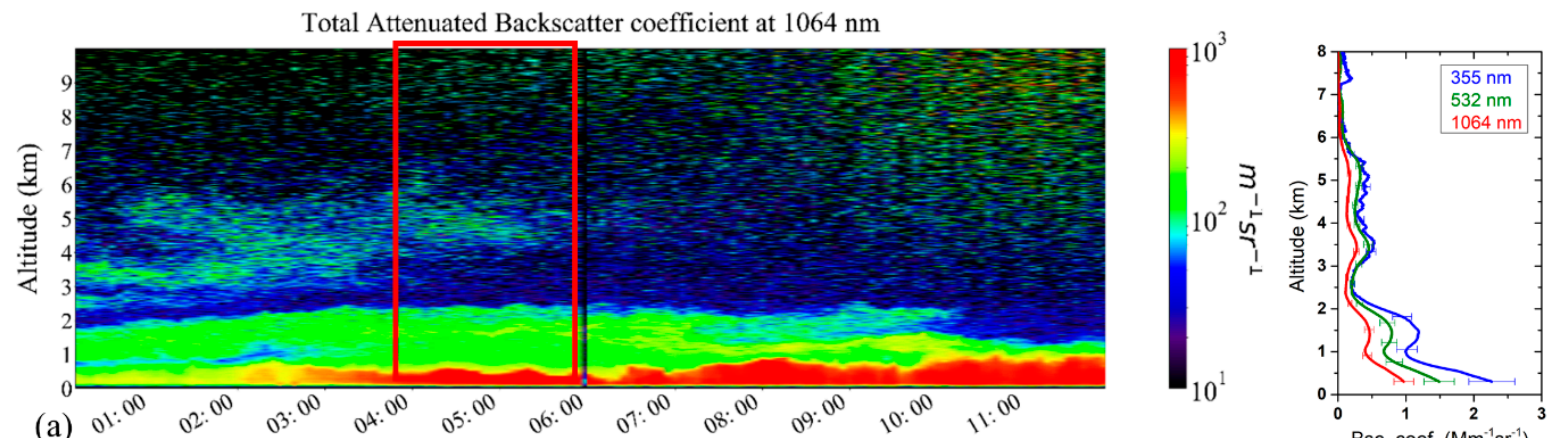

Time (UTC)

Volume Linear Depolarization Ratio at $532 \mathrm{~nm}$
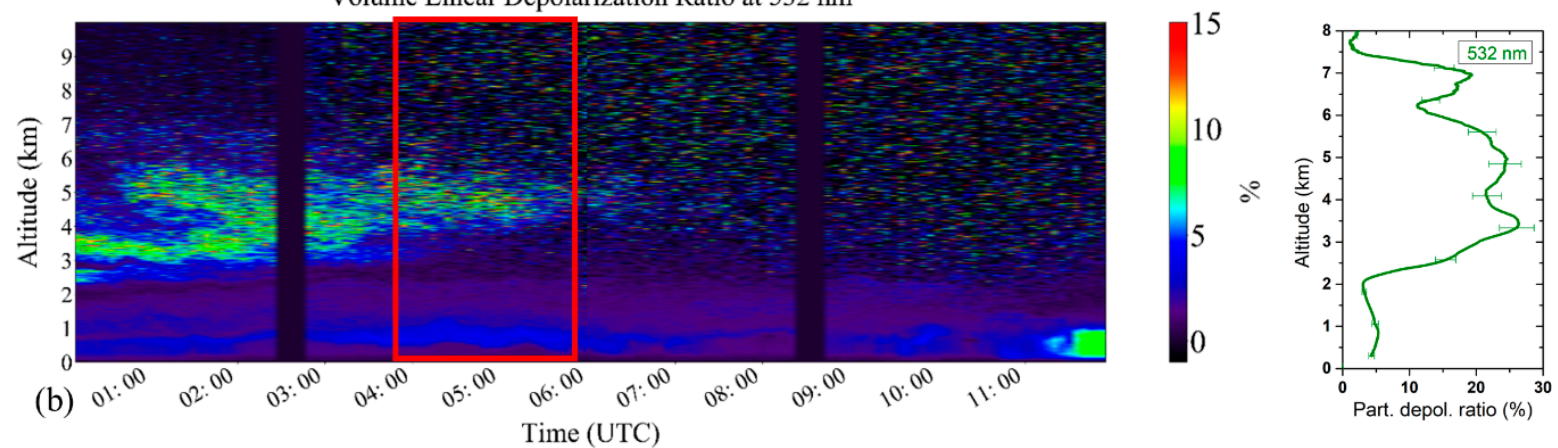

FLEXPART-WRF 5-day backward calculation

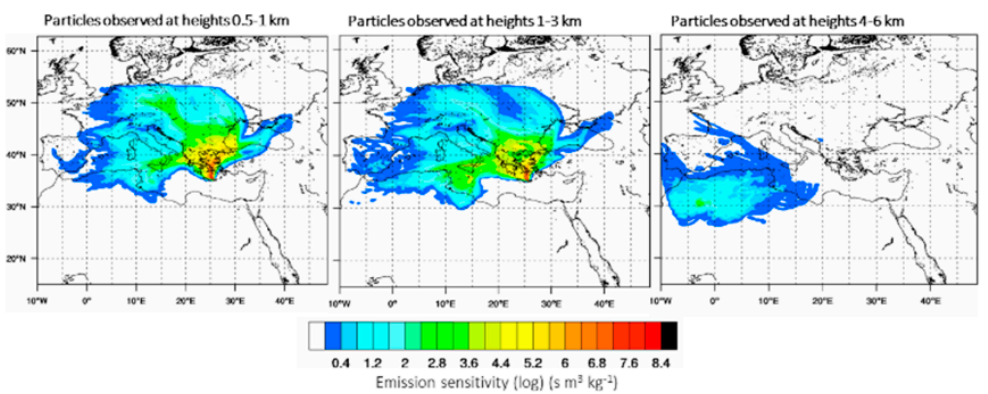

Figure 6. (a) Time-height plot of the total attenuated backscatter coefficient at $1064 \mathrm{~nm}$ alongside with particle backscatter coefficient profiles at 355, 532 and $1064 \mathrm{~nm}$ and (b) time-height plot of the volume linear depolarization ratio alongside with profiles of the particle depolarization ratio at $532 \mathrm{~nm}$ from Polly ${ }^{\mathrm{XT}}$ measurements at Finokalia on 4 July 2014. Red rectangle indicates the time period from 04:00 to 06:00 UTC used for the LIRIC retrieval. The backscatter and depolarization profiles shown correspond to the time period from 00:10 to 02:25 UTC; (c) Five-day backward FLEXPART-WRF calculation of emission sensitivity in $\left[(\log )\left(\mathrm{s} \mathrm{m}^{3} \mathrm{~kg}^{-1}\right)\right]$, for the particles arriving at Finokalia on 4 July 2014 07:00 UTC, at heights 0.5-1 km (left), 1-3 km (middle) and 4-6 km (right) above ground level (a.g.l.), from heights between 0-1 km a.g.l.

Under the presence of two-mainly-coarse mode aerosols (spherical-marine particles and non-spherical-dust particles), we use the 3-mode LIRIC retrieval to derive the particle volume concentration profiles for each mode.

The second case study is a day with marine and polluted continental particles. Total attenuated backscatter coefficient (Figure 7a) shows low aerosol concentration below $3 \mathrm{~km}$, while $\delta_{p}$ values $<5 \%$ indicate spherical particles [99] (Figure 7b). This is also supported by the FLEXPART-WRF backward simulations indicating that the air masses above Finokalia followed mainly western directions having a marine origin with a possible contribution of continental aerosol from southern Italy (Figure 7c). For this case we used the 2-mode LIRIC retrieval to calculate coarse and fine mode volume concentration profiles which we consider to be mainly of marine and continental origin, respectively.

The third case study is a day with polluted continental and marine particles below $3 \mathrm{~km}$, carried by air masses following mainly northern directions (Figure 8). FLEXPARTWRF backward simulations for this day showed that the air masses arriving below $1 \mathrm{~km}$ 
were of both continental and marine origin (Figure 8c). Again, the 2-mode LIRIC retrieval was used to disentangle the contribution of fine mode (continental) and coarse mode (marine) particles, to the total aerosol load.
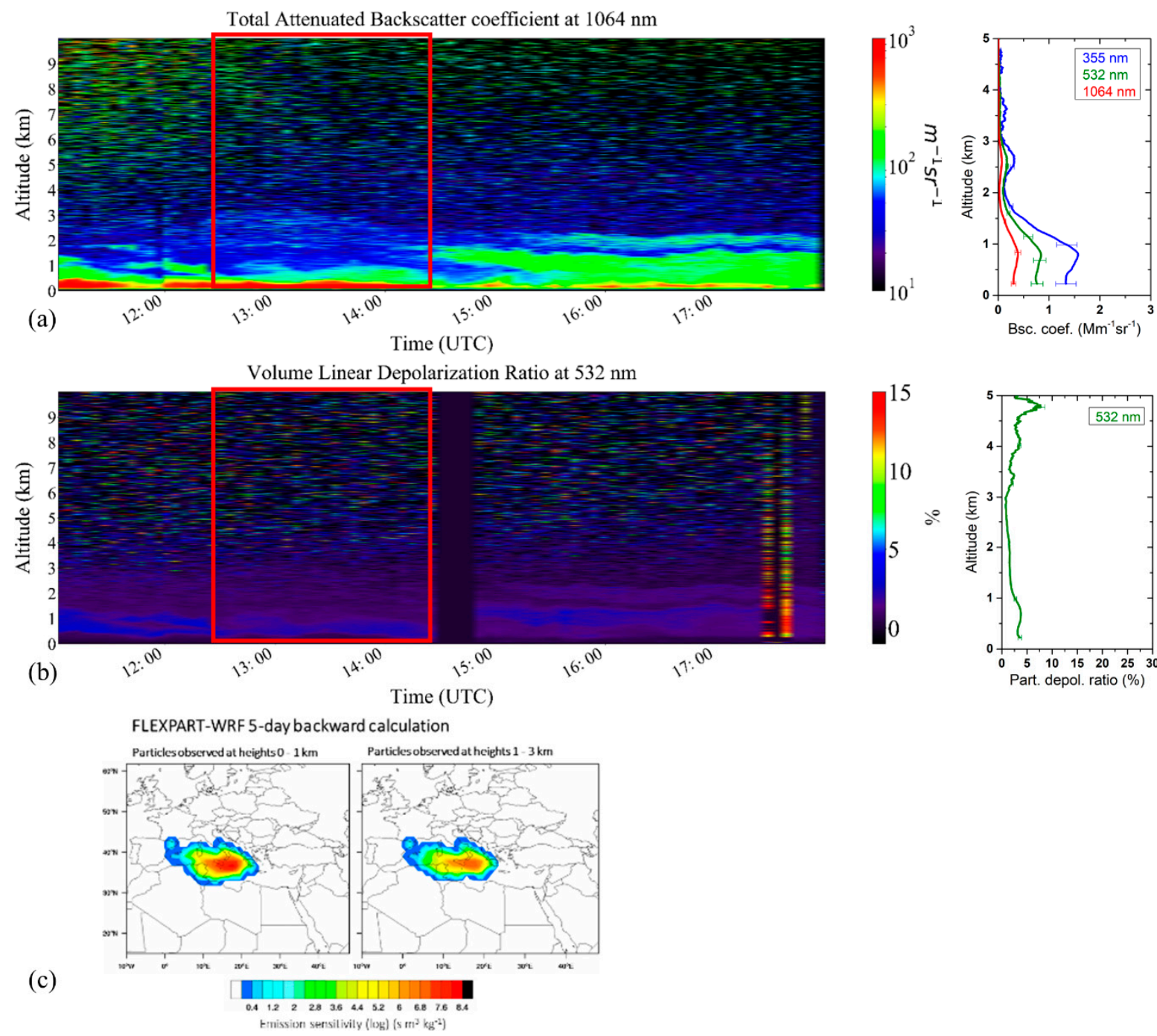

Figure 7. (a) Time-height plot of the total attenuated backscatter coefficient at $1064 \mathrm{~nm}$ alongside with particle backscatter coefficient profiles at 355, 532 and $1064 \mathrm{~nm}$ and (b) time-height plot of the volume linear depolarization ratio alongside with profiles of the particle depolarization ratio at $532 \mathrm{~nm}$ from Polly ${ }^{\mathrm{XT}}$ measurements at Finokalia on 15 July 2014. Red rectangle indicates the time period from 12:30-14:30 UTC used for the LIRIC retrieval. The averaged backscatter and depolarization profiles shown correspond to the time period from 15 July at 23:15 UTC to 16 July at 00:45 UTC; (c) Five-day backward FLEXPART-WRF calculation of emission sensitivity in $\left[(\log )\left(\mathrm{s} \mathrm{m}^{3} \mathrm{~kg}^{-1}\right)\right]$, for the particles arriving at Finokalia on $15 \mathrm{July}$ 2014 14:00 UTC, at heights 0-1 km (left) and 1-3 km (right) a.g.l., from heights between 0-1 km.

\subsection{Comparison of Simulated SSA Emissions and Concentrations}

The comparison of results produced by the M80 and L18 simulations indicates interesting differences revealing the sea-state impact on SSA emissions and, subsequently, on SSA modeling in the troposphere. Regarding the first case, Figure 9a,b shows 10-m wind speed and wave age expressed as the ratio between the wave phase velocity at the peak of the spectrum and the 10-m wind speed on 4 July 2014 at 06:00 UTC. Northerly winds were very intense over the Aegean Sea reaching $22 \mathrm{~m} \mathrm{~s}^{-1}$ at the south of Crete (Figure 9a). This is a typical example of Etesian winds which caused young wind-waves with wave ages up to 2 (Figure 9b). At the same time, SSA emissions estimated using M80 whitecap fraction [32] are shown to follow the wind pattern reaching very high values up to $6 \mu \mathrm{g} \mathrm{m}^{-2} \mathrm{~s}^{-1}$ (Figure 9c). 
This strong dependence on wind speed when using M80 whitecap fraction in the density function of Monahan et al. [62] and Gong et al. [63] is shown to cause high spatial SSA emission variabilities. Contrariwise, the use of L18 whitecap fraction [42] yields lower SSA emission peaks reaching up to $1 \mu \mathrm{g} \mathrm{m}^{-2} \mathrm{~s}^{-1}$ but increases pattern homogeneity, strongly evidenced at several open-sea areas where winds were weak-moderate and wave ages were low. This is explained by the dependence of L18 to sea state supporting whitecaps even under weak-moderate winds. In contrary, M80 almost zeroes the whitecaps for weak winds, ignoring wave propagation.
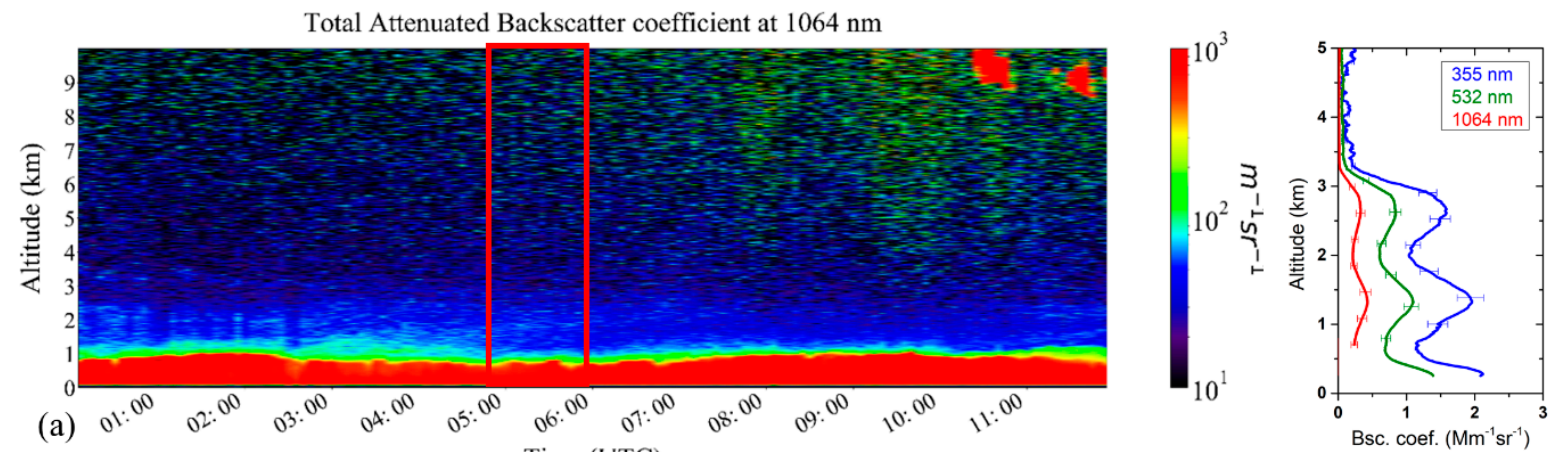

Volume Linear Depolarization Ratio at $532 \mathrm{~nm}$
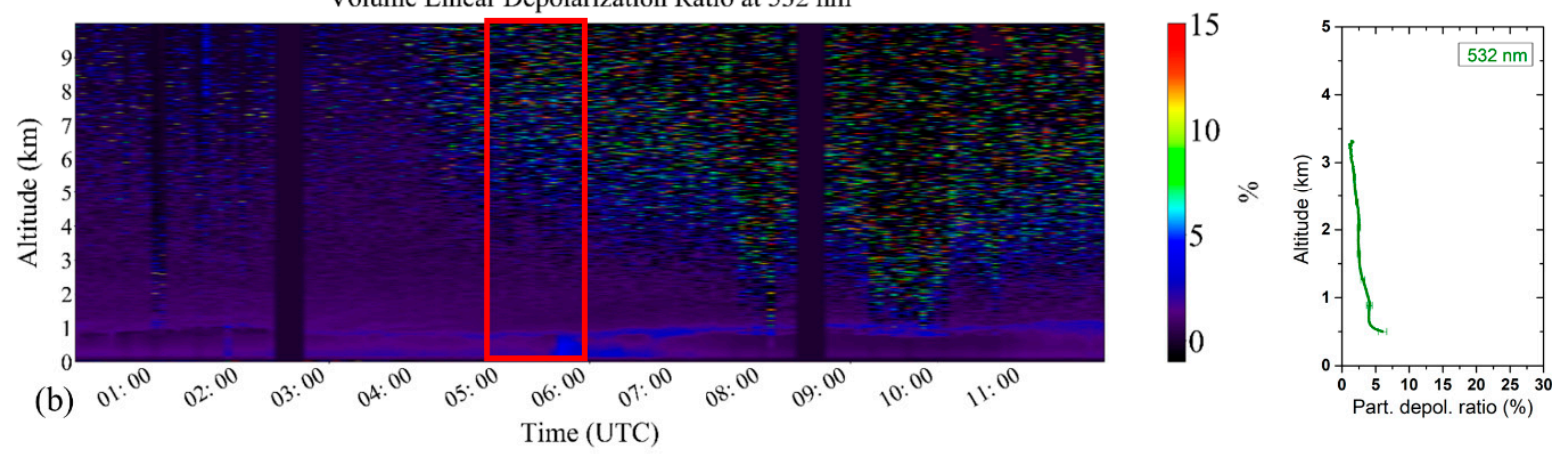

(c)

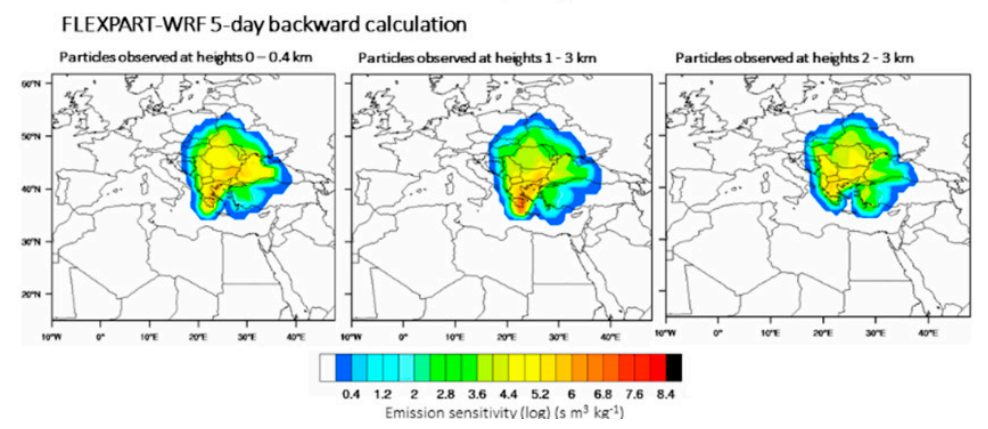

Figure 8. (a) Time-height plot of the total attenuated backscatter coefficient at $1064 \mathrm{~nm}$ alongside with particle backscatter coefficient profiles at 355, 532 and $1064 \mathrm{~nm}$ and (b) time-height plot of the Volume Linear Depolarization Ratio at $532 \mathrm{~nm}$ alongside with profiles of the Particle Linear Depolarization Ratio at $532 \mathrm{~nm}$ from Polly ${ }^{\mathrm{XT}}$ measurements at Antikythera on 15 September 2018. Red rectangle indicates the time period from 05:00 to 06:00 UTC used for the backscatter and depolarization profiles and the LIRIC retrieval; (c) Five-day backward FLEXPART-WRF calculation of emission sensitivity in $\left[(\log )\left(\mathrm{s} \mathrm{m}^{3} \mathrm{~kg}^{-1}\right)\right]$, for the particles arriving at Antikythera on 15 September 2018 05:30 UTC, at heights 0-0.4 km (left), 1-3 km (middle) and 2-3 km (right) a.g.l., from heights between 0-1 km a.g.l.

The second case was characterized by westerly winds locally exceeding 10-12 m s at the southern Aegean Sea on 15 July 2014 at 12:00 UTC (Figure 10a). The lowest wave ages at the Aegean Sea were a little higher than the first case indicating weaker windwave generation (Figure 10b). Nevertheless, it is interesting that fetch for westerly winds is increased for the specific area resulting to wave age values of 1-2 over a wide sea region. This caused a significant difference between M80 and L18 simulated SSA emissions. 
Similarly to the first case, M80 produced SSA emission peaks at wind peak locations, reaching in the range of 1-1.5 $\mu \mathrm{g} \mathrm{m}^{-2} \mathrm{~s}^{-1}$, however, L18 yielded SSA emissions ranging from 0.6 to $0.8 \mu \mathrm{g} \mathrm{m}^{-2} \mathrm{~s}^{-1}$ at a widespread area, reducing spatial heterogeneity.
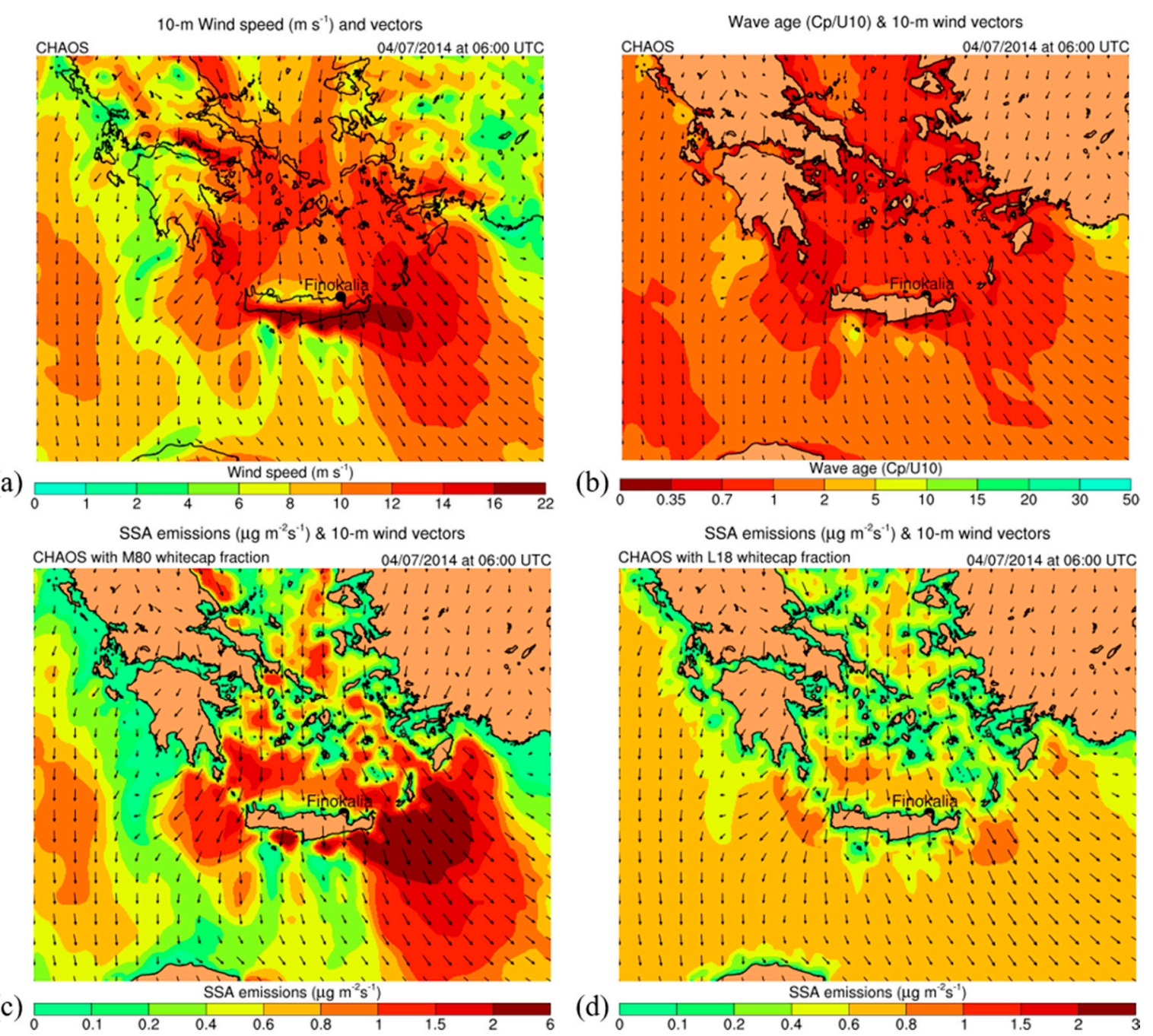

Figure 9. (a) Wind speed $\left(\mathrm{m} \mathrm{s}^{-1}\right)$ at $10 \mathrm{~m}$; (b) wave age expressed as the ratio between the wave phase velocity $\left(\mathrm{m} \mathrm{s}^{-1}\right)$ at the peak of the spectrum and the 10-m wind speed $\left(\mathrm{m} \mathrm{s}^{-1}\right)$; SSA emissions $\left(\mu \mathrm{g} \mathrm{m}^{-2} \mathrm{~s}^{-1}\right)$ for 4 July 2014 at 06:00 UTC estimated using (c) M80 (d) L18 whitecap fraction in CHAOS. 10-m wind vectors are superimposed on all the maps. SSAs initially generated with radius in $0.2-10 \mu \mathrm{m}$ range at $80 \% \mathrm{RH}$ are considered.

The third case was the weakest-wind case with variable winds. On 15 September at 06:00 UTC, northwesterly winds were blowing, reaching $10 \mathrm{~m} \mathrm{~s}^{-1}$ locally at the southeastern Aegean Sea (Figure 11a). Moreover, winds were too weak at the Ionian Sea. Young waves were generated at the Aegean Sea whilst older waves were propagated at a wide part of the Ionian Sea (Figure 11b). Given the wind speed and wave age patterns, M80 simulated SSA emissions which were significantly lower than the L18 ones, especially at the young sea areas. It is noteworthy that it is the only case in which L18 exceeded the M80 SSA emission maxima, reaching $0.6-0.8$ and $0.4-0.6 \mu \mathrm{g} \mathrm{m}^{-2} \mathrm{~s}^{-1}$, respectively. This confirms that the L18 parameterization is dependent not only on wind speed but also on the relative propagation of winds and waves determining wind-wave generation and whitecapping. 

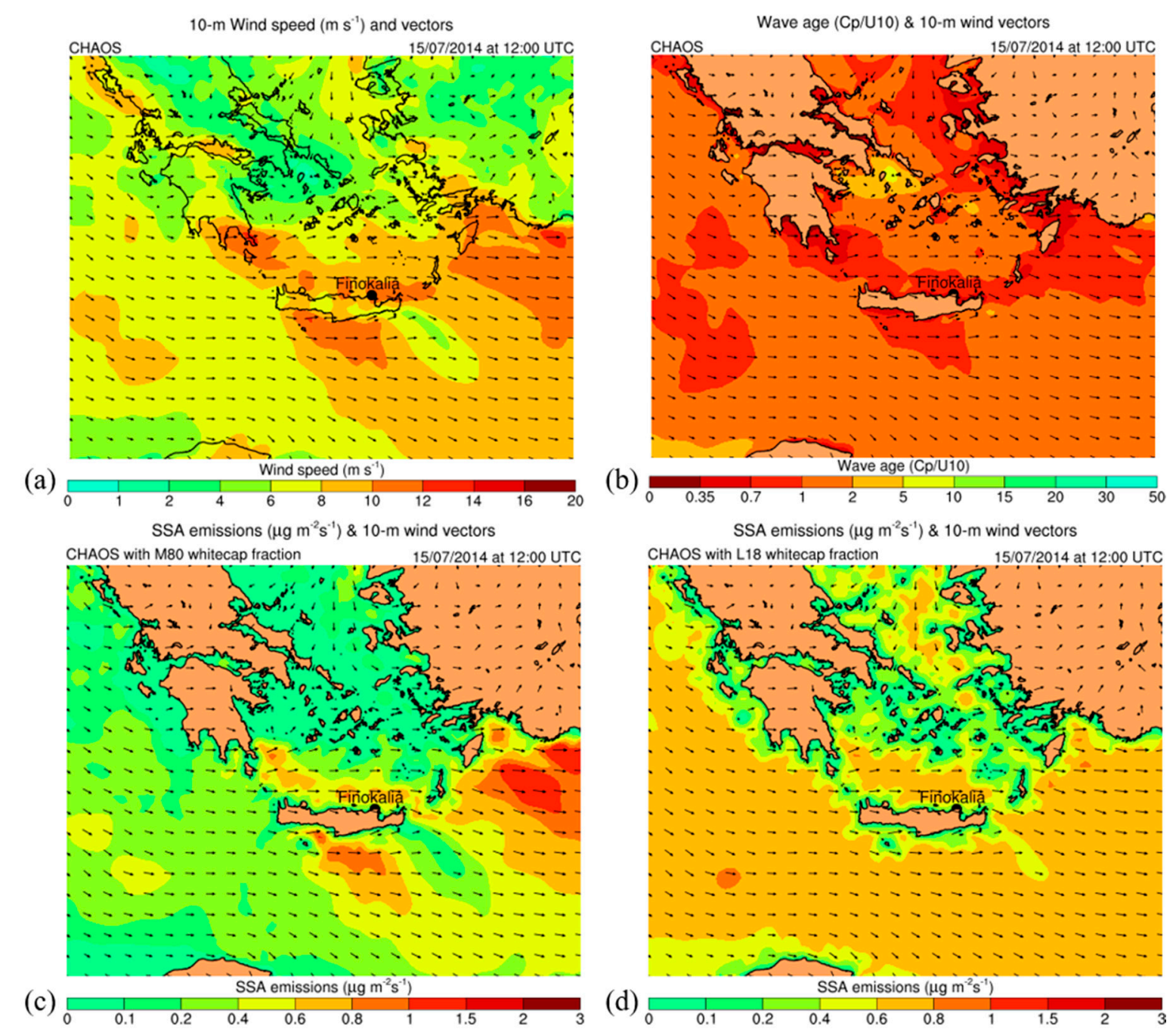

Figure 10. (a) Wind speed $\left(\mathrm{m} \mathrm{s}^{-1}\right)$ at $10 \mathrm{~m}$; (b) wave age expressed as the ratio between the wave phase velocity (m s${ }^{-1}$ ) at the peak of the spectrum and the 10-m wind speed $\left(\mathrm{m} \mathrm{s}^{-1}\right)$; SSA emissions $\left(\mu \mathrm{g} \mathrm{m}^{-2} \mathrm{~s}^{-1}\right)$ for 15 July 2014 at 12:00 UTC estimated using (c) M80 (d) L18 whitecap fraction in CHAOS. 10-m wind vectors are superimposed on all the maps. SSAs initially generated with radius in $0.2-10 \mu \mathrm{m}$ range at $80 \% \mathrm{RH}$ are considered.

Summarizing the three cases, it seems that the SSA emissions in L18 simulations are characterized by a more limited range compared to the M80 ones. For a physical interpretation of the L18 results, we analyzed the dependence of SSA emissions on wind speed, on wave phase velocity at the peak of the spectrum, on wave age and on significant wave height $(\mathrm{SWH})$ (Figure 12a-d). Simulation results at the sea area defined by $19^{\circ}$ $\mathrm{E}-29^{\circ} \mathrm{E}$ and $33^{\circ} \mathrm{N}-41^{\circ} \mathrm{N}$, during the period from 14 July 2014 at 01:00 UTC to 16 July 2014 at 00:00 UTC of the second case study were used. It is important to note that the behavior of the two parameterizations was similar in the three case studies and thus only the results of the second case study are presented in Figure 12. As shown in Figure 12a, L18 (red) yielded a more complex result than the M80 (blue) with more scattered points for L18 as opposed to "an easy to predict/fit" M80 exponential growth and this reflects that L18 approach is more sophisticated including more physical processes in the SSA emissions. L18 SSA emissions increased even under low winds while M80 ones present a substantial increase with the wind speed, finally exceeding $2.4 \mu \mathrm{g} \mathrm{m}^{-2} \mathrm{~s}^{-1}$ over $14 \mathrm{~m} \mathrm{~s}^{-1}$ (Figure 12a). This is explained by Figure 12b,c demonstrating a trend of L18 SSA emissions to increase in low wave phase velocities representing short-wavelength wind-generated waves characterized by low wave ages. Such young waves are usually triggered by local winds even characterized by low-moderate speeds as shown in Figure 12a. These waves totally generate a large 
amount of SSAs by bubble-bursting in whitecaps despite they are not characterized by high SWH, as illustrated in Figure 13d. This is attributed to the fact that young waves rapidly break trapping air in upper ocean increasing whitecapping. The maxima of L18 SSA emissions occurred for wave ages $\sim 0.35$, indicating very young waves and maxima of whitecap fraction. This is explained by Equation (7) of L18 whitecap fraction having the wave age value of 0.35 as turning point of the two equation branches [42].

(a)

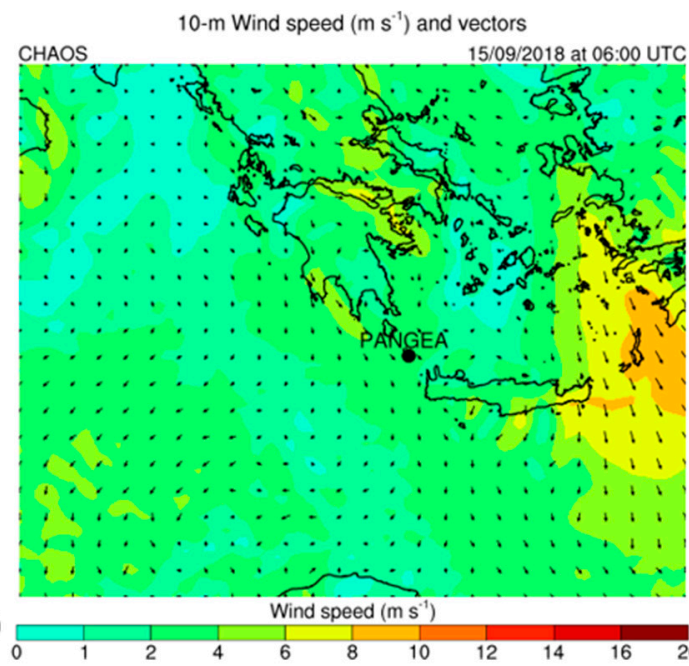

SSA emissions $\left(\mu \mathrm{g} \mathrm{m}^{-2} \mathrm{~s}^{-1}\right)$ \& 10-m wind vectors

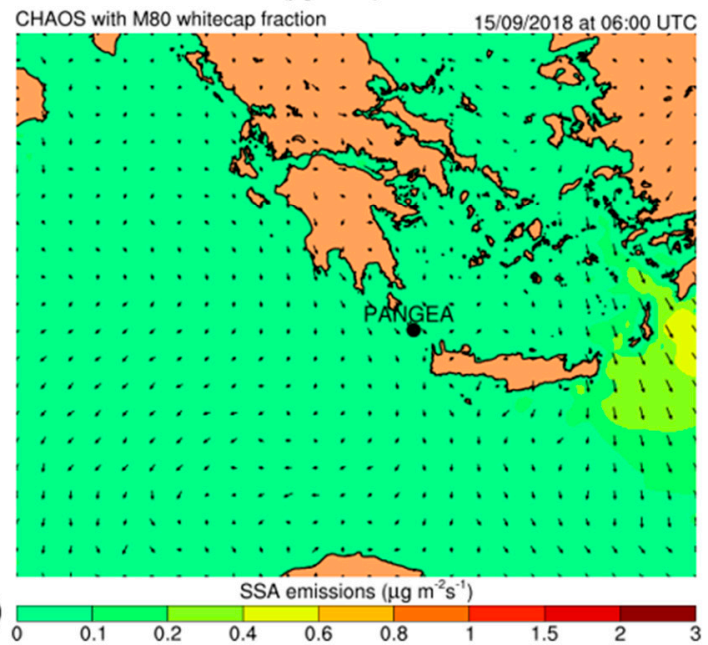

(b)

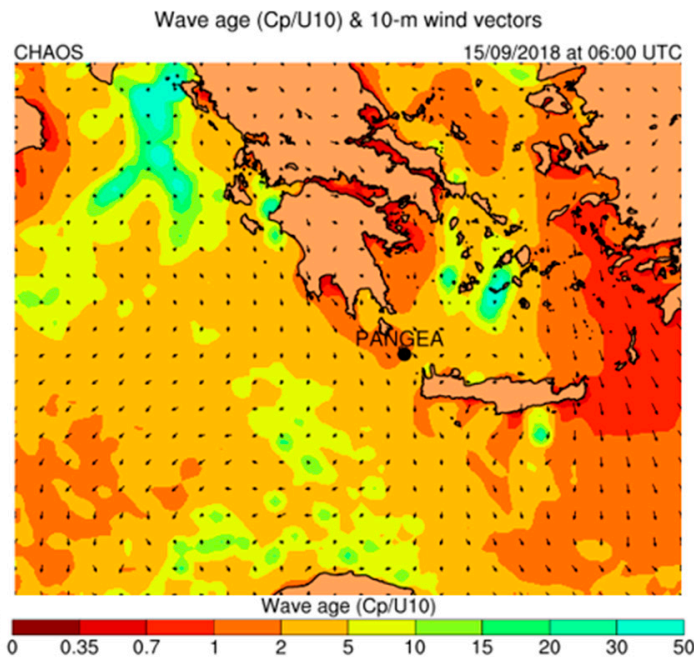

SSA emissions $\left(\mu \mathrm{g} \mathrm{m}^{-2} \mathrm{~s}^{-1}\right) \& 10-\mathrm{m}$ wind vectors

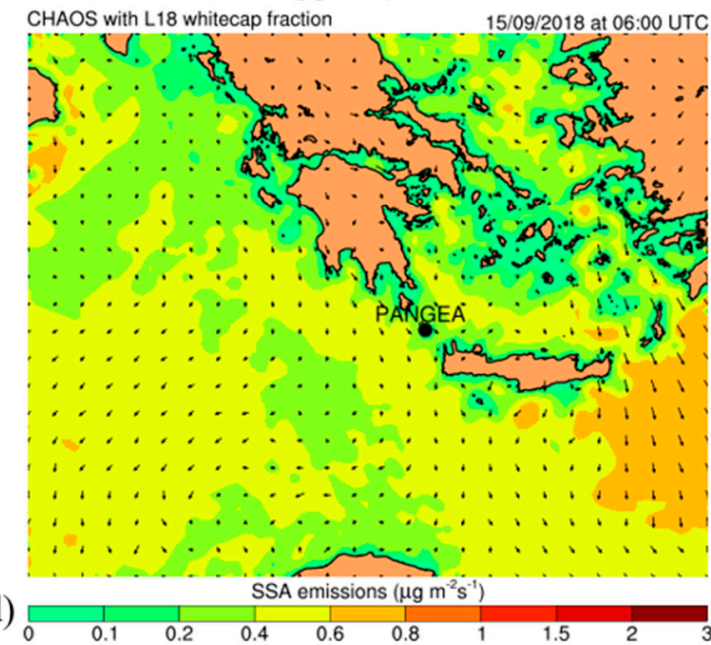

Figure 11. (a) Wind speed $\left(\mathrm{m} \mathrm{s}^{-1}\right)$ at $10 \mathrm{~m}$; (b) wave age expressed as the ratio between the wave phase velocity (m s${ }^{-1}$ ) at the peak of the spectrum and the 10-m wind speed $\left(\mathrm{m} \mathrm{s}^{-1}\right)$; SSA emissions $\left(\mu \mathrm{g} \mathrm{m}^{-2} \mathrm{~s}^{-1}\right)$ for 15 September 2018 at 06:00 UTC estimated using (c) M80 (d) L18 whitecap fraction in CHAOS. 10-m wind vectors are superimposed on all the maps. SSAs initially generated with radius in $0.2-10 \mu \mathrm{m}$ range at $80 \% \mathrm{RH}$ are considered.

Our results agree in general with the previous study by Piazzola et al. [40] who found a different wave age threshold (i.e., 0.69) for whitecap fraction maxima, using a sea-state dependent model for sea-spray fluxes, following the whitecap fraction parameterization of Lafon et al. [38]. On the other hand, the total air-bubble trapping of one young wave is weaker than one larger wave that is usually related to stronger winds. This is evident in M80 results yielding higher SSA emissions under high winds, considering that large waves cause more intense whitecapping. However, over a specific area, the number of small rapidly-generated waves is larger than the number of bigger waves and thus rapidlygenerated waves totally cause even comparable or higher SSA emissions than waves with high SWH (Figure 12d). It is interesting for L18 that low wind speeds in the range of 2-6 $\mathrm{m} \mathrm{s}^{-1}$ blowing over sea with SWHs in 0.1-1.5 $\mathrm{m}$ range can sharply trigger SSA emis- 
sions exceeding $0.8-1 \mu \mathrm{g} \mathrm{m}^{-2} \mathrm{~s}^{-1}$ (Figure 12a,c,d). This wave-age dependent behavior of L18 parameterization explains the SSA emission variabilities and homogeneity differences that are shown in the analysis of the three cases in the previous paragraphs. Totally over the sea area defined by $19^{\circ} \mathrm{E}-29^{\circ} \mathrm{E}$ and $33^{\circ} \mathrm{N}-41^{\circ} \mathrm{N}, \mathrm{M} 80$ and L18 simulations yielded average SSA emissions of approximately $136 \mathrm{~kg} \mathrm{~s}^{-1}$ and $270 \mathrm{~kg} \mathrm{~s}^{-1}$, respectively, considering the period from 14 July 2014 at 01:00 UTC to 16 July 2014 at 00:00 UTC. The high total emission differences between M80 and L18 are attributed to the increased sensitivity of L18 even under weak winds as previously analyzed.
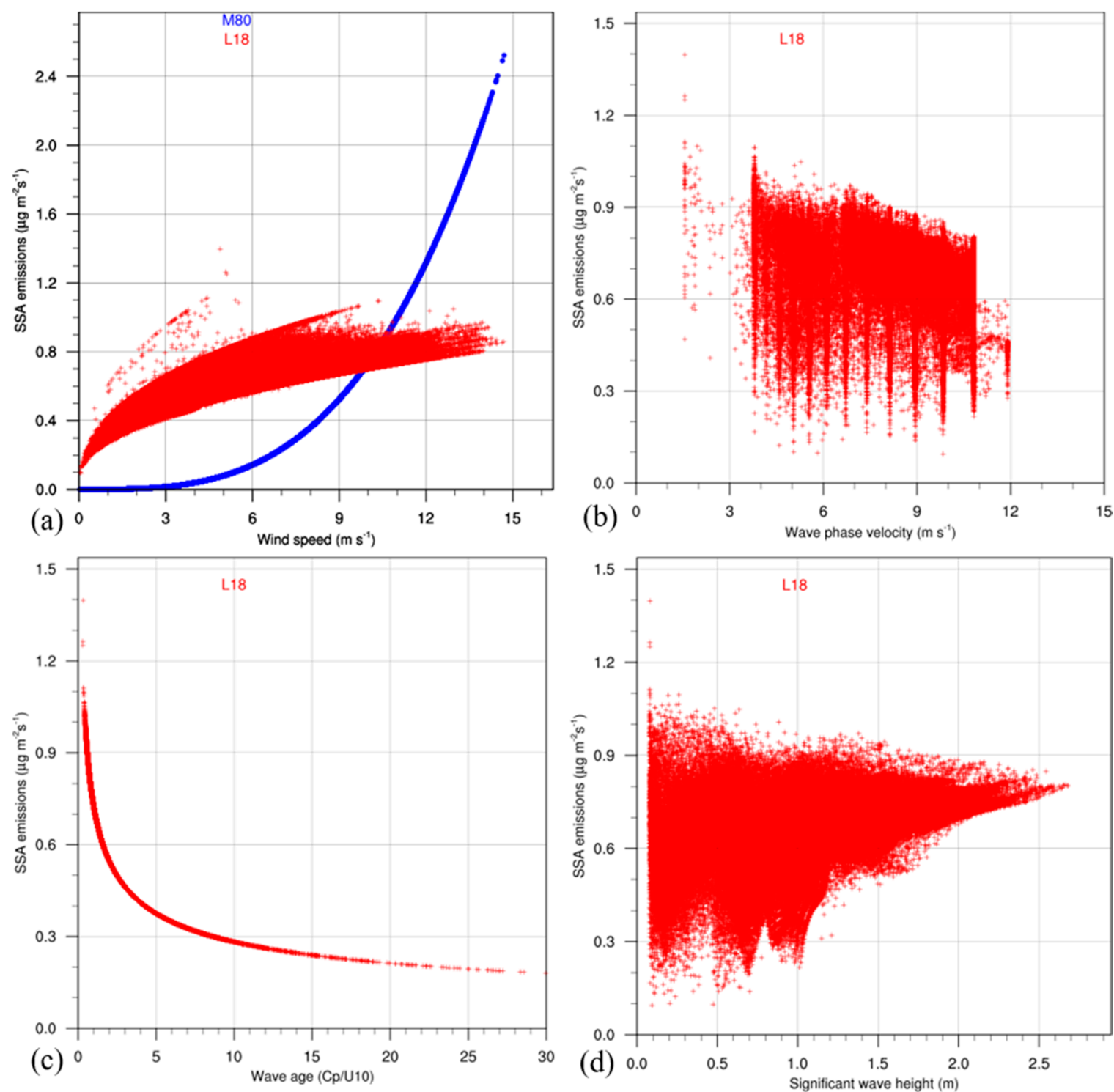

Figure 12. Dependence of SSA emissions $\left(\mu \mathrm{g} \mathrm{m}^{-3} \mathrm{~s}^{-1}\right)$ on (a) the wind speed $\left(\mathrm{m} \mathrm{s}^{-1}\right)$, (b) the wave phase velocity $\left(\mathrm{m} \mathrm{s}^{-1}\right)$, (c) the wave age expressed as the ratio between the wave phase velocity $\left(\mathrm{m} \mathrm{s}^{-1}\right)$ and the wind speed $\left(\mathrm{m} \mathrm{s}^{-1}\right)$ and $(\mathrm{d})$ the significant wave height $(\mathrm{m})$. The $\mathrm{X}-\mathrm{Y}$ diagrams refer to simulation results at the sea area defined by $19^{\circ} \mathrm{E}-29^{\circ} \mathrm{E}$ and $33^{\circ}$ $\mathrm{N}-41^{\circ} \mathrm{N}$, during the period from 14 July 2014 at 01:00 UTC to 16 July 2014 at 00:00 UTC. Blue and red colors represent CHAOS simulations using M80 and L18 whitecap fractions, respectively. SSAs initially generated with radius in $0.2-10 \mu \mathrm{m}$ range at $80 \% \mathrm{RH}$ are considered. 

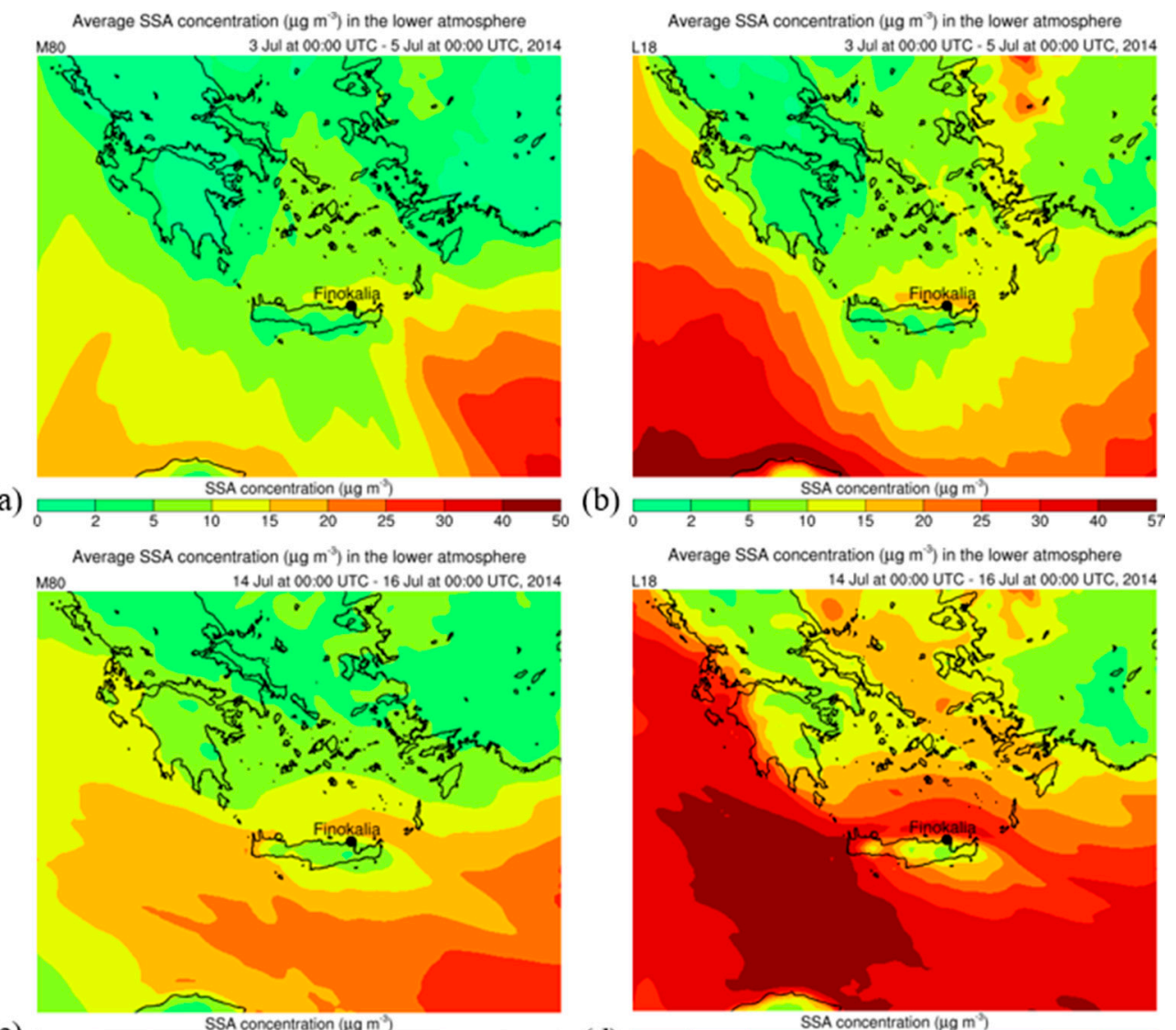

(c)
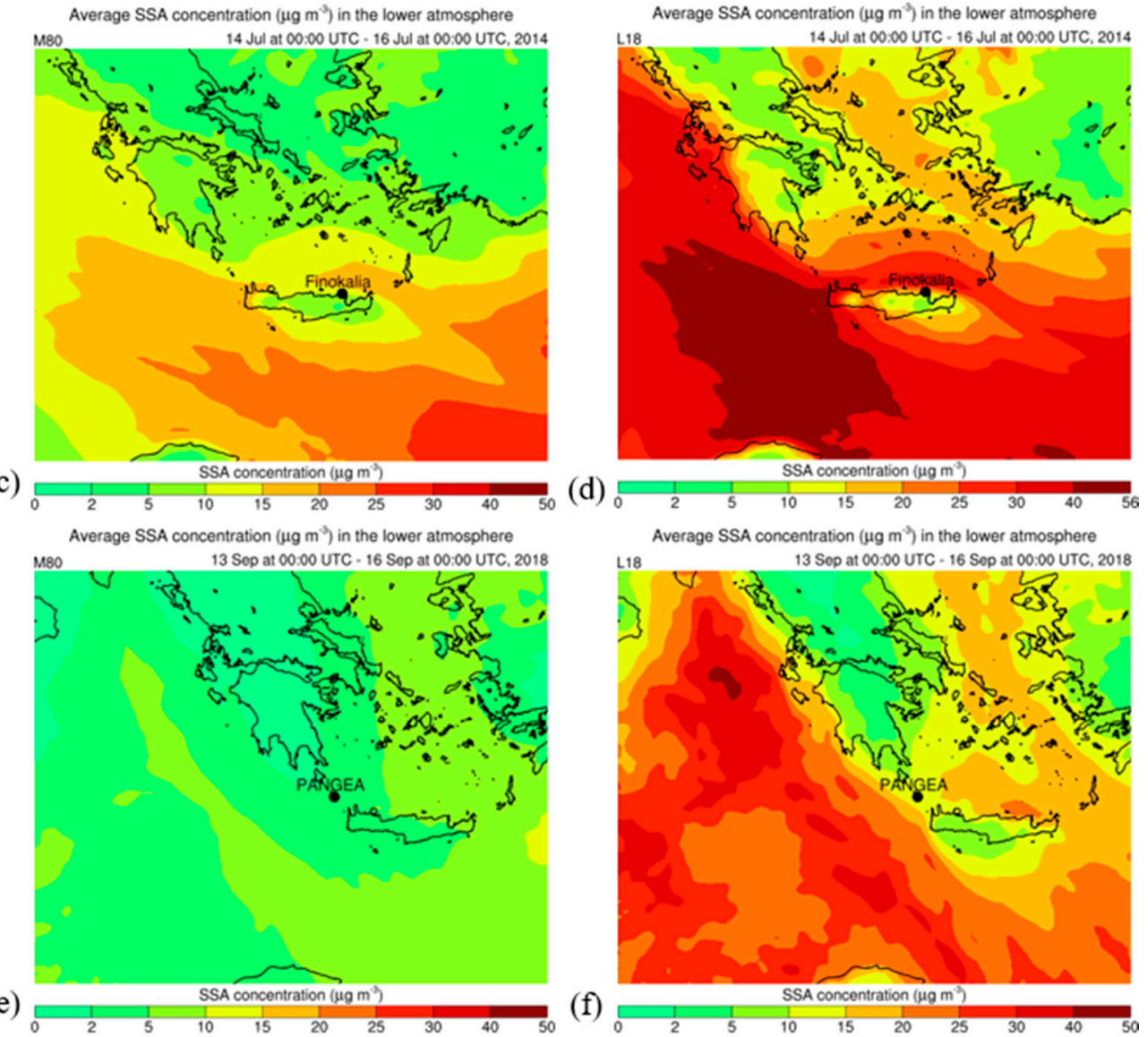

Figure 13. Vertically and temporarily averaged SSA concentrations $\left(\mu \mathrm{g} \mathrm{m}^{-3}\right)$ in the first $\sim 400 \mathrm{~m}$ from the surface for the periods: 3 July at 00:00 UTC-5 July at 00:00 UTC, 2014, using (a) M80 (b) L18 whitecap fraction, 14 July at 00:00 UTC-16 July at 00:00 UTC, 2014, using (c) M80 (d) L18 whitecap fraction and 13 September at 00:00 UTC-16 September at 00:00 UTC, 2018, using (e) M80 (f) L18 whitecap fraction. SSAs initially generated with radius in $0.2-10 \mu \mathrm{m}$ range at $80 \% \mathrm{RH}$ are considered.

Starting from the lower troposphere, we compare SSA concentrations derived by the M80 and L18 simulations for the three case studies. Figure 13a,b indicatively demonstrates M80 and L18 vertically averaged SSA concentrations in the layer 0-400 $\mathrm{m}$ which are also temporarily averaged for the period from 3 July at 00:00 UTC to 5 July at 00:00 UTC of 2014. L18 simulated higher SSA concentrations reaching $57 \mu \mathrm{g} \mathrm{m}^{-3}$ in comparison with M80 hardly exceeding $30 \mathrm{mg} \mathrm{m}^{-3}$. Hence, the comparison between M80 and L18 SSA concentrations is reversed compared to SSA emissions. This is explained by the more homogeneous emissions of L18 that despite not reaching the peaks of M80, they resulted in 
overall higher sea-salt concentrations in the lower atmosphere from wider area. A similar behavior of L18 and M80 simulations is also evidenced over $400 \mathrm{~m}$ with gradual reduction of concentrations. It is also interesting that SSA concentration maxima are located at the south of the Aegean and Ionian Seas. This is attributed to the southward horizontal transport of SSAs by the intense north Etesian winds. Also, fetches at the southern Aegean and Ionian Seas are larger than the northern Aegean Sea and the Adriatic Sea, respectively, contributing to the increase of SSA concentrations at the south. As far as the second case is concerned, the respective L18 and M80 average concentrations for the period from 14 July at 00:00 UTC to 16 July at 00:00 UTC of 2014 presented similar differences as the first case reaching 56 and $\sim 30 \mu \mathrm{g} \mathrm{m}^{-3}$, respectively Figure 13c,d. Compared with M80, L18 simulated higher SSA concentrations over a wide area of the Ionian Sea. This is explained by the large fetch of the central-eastern Mediterranean Sea resulting to significant wind-wave generation, followed by eastward transport of SSAs with the westerly winds blowing over this area. The third case is also characterized by marked spatial differences. The respective L18 and M80 average SSA concentrations from 13 September at 00:00 UTC to 16 September at 00:00 UTC of 2018 presented high differences especially over the Ionian Sea reaching $40-50$ and $5-10 \mu \mathrm{g} \mathrm{m}^{-3}$, respectively (Figure 13e,f). This is attributed to the feasibility of the L18 parameterization to produce SSAs even under low-moderate winds at wide areas, discussed in previous paragraphs. Given the weak horizontal transport of SSAs under weak winds, L18 caused vertically accumulated SSAs over wide sea-areas.

\subsection{Evaluation of Simulated SSA Concentrations in the Lower Atmosphere}

The simulations were characterized by high differences regarding SSA emissions and concentrations and, thus, the comparison of results with measurements was necessary to assess the effects of the newly implemented L18 sea-state dependent whitecap fraction parameterization [42]. Model results were assessed using in-situ SSA concentration measurements and lidar-derived SSA concentrations at Finokalia station (Crete, Greece) on 4 and 15 July 2014 (Figure 14a-d) and at PANGEA observatory (Antikythera, Greece) on 15 September 2018 (Figure 15a,b). At a glance, Figures 14 and 15 reveal striking differences between results from both parametrizations and the observations. This is itself a significant finding as the only difference of the SSA simulations is the whitecap fraction in the density function.

More specifically, Figure 14a shows dry SSA mass concentration vertical profiles from the height of the Finokalia station up to $2000 \mathrm{~m}$ as resulted by the M80 (blue line) and L18 (red line) simulations for 4 July 2014 at 04:00-06:00 UTC. Model results were vertically interpolated at the lidar measurement height. The same plot demonstrates LIRIC dry SSA mass concentrations (aquamarine solid line) and its uncertainty (aquamarine dashed lines) estimated by lidar/sun-photometer derived volume concentrations (ppb) in 0.439-10 $\mu \mathrm{m}$ radius range (ambient $\mathrm{RH}$ ) applying eq 9 and using the $\mathrm{RH}$ profile from the model for the same hours as shown in Figure 14b. Approximate surface LIRIC concentration (aquamarine dot) considering $0.439-5 \mu \mathrm{m}$ radius range (ambient $\mathrm{RH}$ ) is also shown in Figure 14a. In the first $250 \mathrm{~m}$ from the ground, where the lidars are blind, LIRIC retrievals are only an approximation (aquamarine dashed lines in the profile), as they assume homogenous mixing conditions for the retrieval in these heights, which is not always the case. In-situ measured (black dot) dry SSA mass concentration from 4 July at 00:00 UTC to 5 July at 00:00 UTC, 2014 and the respective M80 (blue dot) and L80 (red dot) simulated dry SSA mass concentrations for the same periods are also shown in Figure 14a. It is important to note that model results refer to the dry mass included in bin1, bin2 and bin3 of SSAs initially generated with radius in $0.2-10 \mu \mathrm{m}$ range at $80 \% \mathrm{RH}$ (Table 2 ). Moreover, lidar/sunphotometer derived volume concentrations calculated with LIRIC refer to SSAs with radius in $0.439-10 \mu \mathrm{m}$ range (Table 2). Furthermore, in-situ measured concentration refers to the dry mass included in PM10 ( $\mathrm{r}<5 \mu \mathrm{m})$ SSAs collected under ambient RH conditions (Table 2). For the evaluation against in-situ measurement, M80 (blue dot) and L18 (red dot) model dry mass concentrations of SSAs initially generated in $0.2-5 \mu \mathrm{m}$ range at $80 \% \mathrm{RH}$ were calculated considering the results of bin1, bin2 and 2/7 of bin3. 

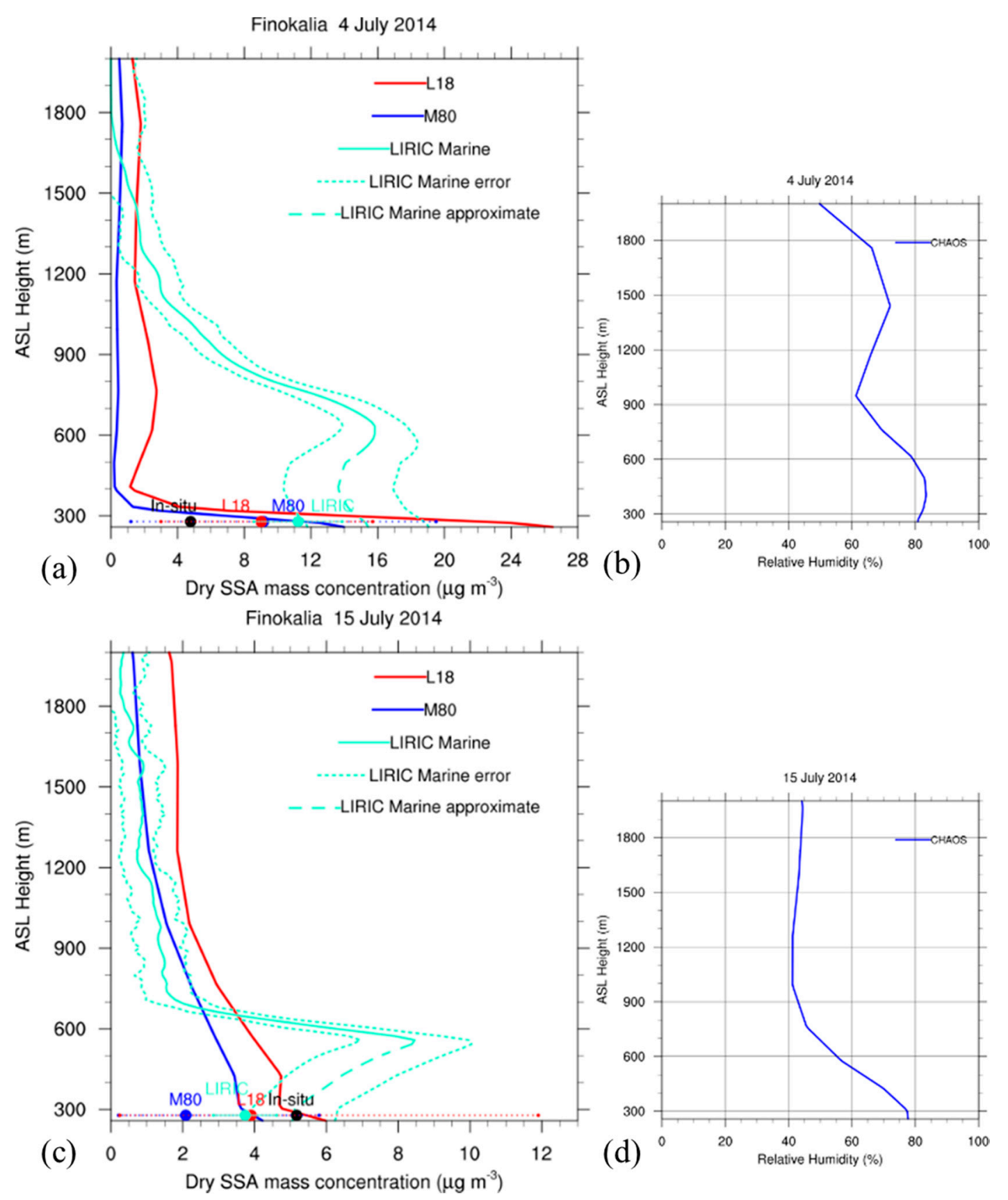

Figure 14. (a) Dry SSA $(r=0.2-10 \mu \mathrm{m}$ at $80 \% \mathrm{RH})$ mass concentration $\left(\mu \mathrm{g} \mathrm{m}^{-3}\right)$ vertical profiles from the Finokalia station height up to $2000 \mathrm{~m}$ as resulted by M80 (blue line) and L18 (red line) simulations for 4 July 2014 at 04:00-06:00 UTC. LIRIC (aquamarine solid line) dry SSA ( $r=0.439-10 \mu \mathrm{m}$ at ambient RH) mass concentrations estimated by lidar/sunphotometer derived volume concentrations (ppm) using eq. 9 and (b) model-estimated RH (\%) vertical profiles from the Finokalia station height $(258 \mathrm{~m})$ up to $2000 \mathrm{~m}$ for 4 July 2014 at 04:00-06:00 UTC. The uncertainty and the approximate 250-m layer of LIRIC are also illustrated by aquamarine dashed lines. Aquamarine dot represents the approximate surface LIRIC concentration considering $\mathrm{r}=0.439-5 \mu \mathrm{m}$ at ambient $\mathrm{RH}$. In-situ measured (black dot) dry SSA ( $\mathrm{r}<5 \mu \mathrm{m}$ at ambient $\mathrm{RH}$ ) mass concentrations for the period from 4 July at 00:00 UTC to 5 July at 00:00 UTC as well as the respective M80 (blue dot) and L80 (red dot) simulated dry SSA ( $\mathrm{r}=0.2-5 \mu \mathrm{m}$ at $80 \% \mathrm{RH})$ mass concentrations for the same period are also shown. 24-h range and error bars for the model and LIRIC surface concentrations, respectively, are also shown. Similarly, (c,d) refer to the second case. Model and LIRIC vertical profiles as well as surface LIRIC value (i.e., aquamarine dot) refer to 15 July 2014 at 12:30-14:30 UTC while in-situ measurement (black dot) and the respective model (i.e., blue and red dots) values refer to the period from 15 July at 00:00 UTC to 16 July at 00:00 UTC, 2014. 


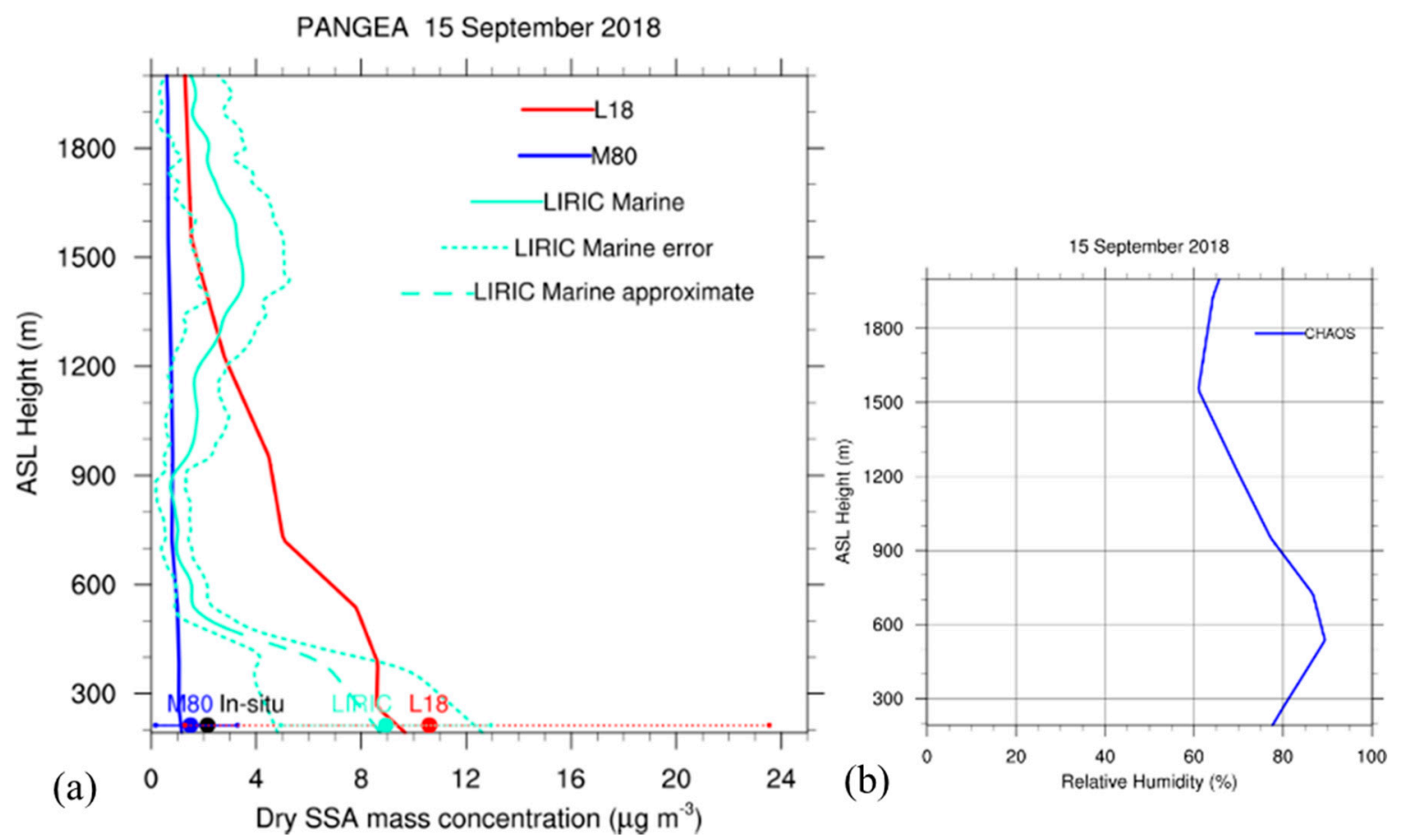

Figure 15. Similarly with Figure 14, $(\mathbf{a}, \mathbf{b})$ refer to the third case at the PANGEA observatory (193 m). Model and LIRIC vertical profiles as well as surface LIRIC value (i.e., aquamarine dot) refer to 15 September 2018 at 05:00-06:00 UTC while in-situ measurement (black dot) and the respective model (i.e., blue and red dots) values refer to the period from 14 September at 16:00 UTC to 15 September at 12:00 UTC. A significant difference with the two other cases of Figure 14 is the SSA radius range considered in the in-situ measurement. In-situ measured concentration refers to the dry mass included in TSP SSAs under ambient RH conditions and, thus, the maximum model SSA radius range $(r=0.2-10 \mu \mathrm{m}$ at $80 \% \mathrm{RH})$ has been considered for the respective model concentrations (i.e., blue and red dots) extraction. 20-h range and error bars for the model and LIRIC surface concentrations, respectively, are also shown.

Table 2. Radius $\mathrm{r}(\mu \mathrm{m})$ range of modeled, lidar and in-situ measured SSAs considered in the evaluation of three case studies. Radius range refers to $80 \% \mathrm{RH}$ and ambient $\mathrm{RH}$ for the modeled and measured SSAs, respectively. TSP include even very fine and very coarse SSAs but the majority matches with the respective size of modeled SSAs.

\begin{tabular}{|c|c|c|c|}
\hline \multirow[b]{2}{*}{ Evaluation Type } & \multirow[b]{2}{*}{ Evaluation Period } & \multicolumn{2}{|c|}{ Radius $\mathbf{r}(\mu \mathrm{m})$ Range } \\
\hline & & $\begin{array}{c}\text { Model } \\
(80 \% \text { RH) }\end{array}$ & $\begin{array}{l}\text { Measurements } \\
\text { (Ambient RH) }\end{array}$ \\
\hline \multirow{3}{*}{ Against lidar } & 4 July 2014 at 04:00-06:00 UTC & $0.2-10$ & $0.439-10$ \\
\hline & 15 July 2014 at 12:30-14:30 UTC & $0.2-10$ & $0.439-10$ \\
\hline & 15 September 2014 at 05:00-06:00 UTC & $0.2-10$ & $0.439-10$ \\
\hline \multirow{3}{*}{ Against in-situ } & 4 July at 00:00 UTC-5 July at 00:00 UTC, 2014 & $0.2-5$ & PM10 $(\mathrm{r}<5 \mu \mathrm{m})$ \\
\hline & 15 July at 00:00 UTC-16 July at 00:00 UTC, 2014 & $0.2-5$ & PM10 $(\mathrm{r}<5 \mu \mathrm{m})$ \\
\hline & 14 September at 16:00 UTC-15 September at 12:00 UTC, 2018 & $0.2-10$ & TSP \\
\hline
\end{tabular}

Comparing with M80, L18 resulted to higher dry SSA mass concentrations from the surface to $2 \mathrm{~km}$ having better agreement with LIRIC measurements, especially at 300-350 m (Figure 14a). Nevertheless, both simulations underestimated SSA mass concentration from the station height to $1450 \mathrm{~m}$ for L18 and $1650 \mathrm{~m}$ for M80 while a slight overestimation is evidenced higher up to $2000 \mathrm{~m}$, more pronounced for L18. Similar underestimation of the modeled SSA mass concentrations for this period at Finokalia station has been also reported in a previous study by Tsekeri et al. [90] who used the RAMS-ICLAMS modeling system [16] with M80 parameterization for describing the SSA fluxes. However, using the L18 scheme resulted in reduced mean bias error (MBE) and root mean square error 
(RMSE) as presented in Table 3. Despite the fact that the statistical metrics are not overall satisfying in this case study, the L18 run reduced the RMSE (by 14.2\%) compared with M80. An explanation for the underestimation sharply observed over $350-400 \mathrm{~m}$ is a probable inaccuracy of the model to vertically circulate large SSA quantities in the marine boundary layer under strong Etesian winds. An additional reason of the underestimation, especially using the M80 parameterization, is that the model does not thoroughly represents SSAs produced by wave breaking in the surf zone [100], that contribute sometimes a large part in the total SSAs produced. In contrast to the comparison against LIRIC, the comparison against the in-situ measurement indicated similar overestimation for both simulations. Nevertheless, it is important to note here that Etesian winds are characterized by a distinct diurnal cycle [101] with a different impact on the M80 and L18 SSA emissions as evidenced by the 24-h ranges in Figure 14a. It is interesting that, comparing the near-surface results, evaluation reveals that the model overestimated against the in-situ measurement and underestimated against LIRIC measurements. This is partially attributed to the different periods of evaluations against the in-situ (4 July at 00:00 UTC to 5 July at 00:00 UTC) and the LIRIC measurements (4 July 2014 at 04:00-06:00 UTC) but also to the incapability of LIRIC to provide trustworthy retrievals close to the surface (in the overlap region).

Table 3. Results of M80 and L18 statistical evaluation against lidar measurements (LIRIC marine) from the height of stations up to $2000 \mathrm{~m}$. Mean Bias Error (MBE) and Root Mean Square Error (RMSE) are presented.

\begin{tabular}{ccccc}
\hline \multirow{2}{*}{ Evaluation Period } & \multicolumn{2}{c}{ MBE } & \multicolumn{2}{c}{ RMSE } \\
\cline { 2 - 5 } & M80 & L18 & M80 & L18 \\
\hline 4 July 2014 at 04:00-06:00 UTC & -5.22 & -3.5 & 7.75 & 6.65 \\
15 July 2014 at 12:30-14:30 UTC & -0.48 & 0.47 & 1.6 & 1.51 \\
15 September 2018 at 05:00-06:00 UTC & -1.97 & 1.43 & 2.78 & 2.75 \\
\hline
\end{tabular}

Similarly to the first case, Figure $14 \mathrm{c}$ shows the simulated and measured dry SSA mass concentration vertical profiles up to $2000 \mathrm{~m}$ for 15 July 2014 at 12:30-14:30 UTC. Figure $14 \mathrm{~d}$ shows the RH profile from the model for the same hours used for the estimation of the dry LIRIC profile. Moreover, the in-situ measurements and the respective M80 and L80 simulated values refer to the period from 15 July at 00:00 UTC to 16 July at 00:00 UTC, 2014 (Figure 14b). Furthermore, the particle radii considered are the same as the first case (Table 2). Regarding the evaluation against LIRIC measurements, M80 simulation presents underestimation up to $700 \mathrm{~m}$ and overestimation from $700 \mathrm{~m}$ to $2000 \mathrm{~m}$ while L18 simulation overestimates up to 300, underestimates from 300 to $700 \mathrm{~m}$ and overestimates from 700 to $2000 \mathrm{~m}$ (Figure 14b). In total, the underestimation of M80 was turned to overestimation in the L18 simulation as indicated by MBE values while L18 yielded better RMSE (5.6\% reduction) as shown in Table 3. Nevertheless, it is interesting that significant performance contrast is demonstrated vertically for the two simulations. L18 presents much better agreement with LIRIC up to $700 \mathrm{~m}$ determining the total statistical scores, however, M80 presents better fit with LIRIC values from 700 to $2000 \mathrm{~m}$. A quite possible explanation of the L18 overestimation over $700 \mathrm{~m}$ is the reflection of near-surface conditions, given the fact that the aerosol simulations used the same atmospheric modeling, as aerosol-to-atmosphere feedbacks were not considered in this study. Specifically, as has been illustrated in Figures 10d and 13c,d, L18 resulted to plenty of SSAs near the surface even under low winds contributing to more SSAs which would be potentially propagated higher. In contrast to L18, M80 simulated high SSA concentrations only over areas with moderate-high winds. Moreover, L18 better agrees with the in-situ measurement for the period from 15 July at 00:00 UTC to 16 July at 00:00 UTC, compared to the M80 simulation. The evaluation results are better in this case study probably because it is characterized by lower winds, forcing the low-atmosphere underestimation against LIRIC to be reduced. A major difference of this case-study in comparison with the previous case of 4 July, is the 
wind direction. On $15 \mathrm{July}$, the west winds blowing from the southern Ionian Sea were blocked by the high orography of Crete Island and limited amounts of SSAs managed to reach the station of Finokalia. In contrary, the strong northerly winds for the case of 4 July were blowing from the Aegean Sea and the particles arrived directly from the sea to the station of Finokalia which is located at the north coast of Crete. In agreement with the comparison against LIRIC, the evaluation with the in-situ measurements indicated underestimation which was more pronounced for the M80 simulation. This means that compared with M80, L18 simulated much higher SSA emissions during the entire day (i.e., 15 July 2014), as shown by the 24-h ranges (Figure 14c).

As far as the third case is concerned, Figure 15a presents the simulated and measured dry SSA mass concentration vertical profiles from the height of PANGEA observatory up to $2000 \mathrm{~m}$ for 15 September 2018 at 05:00-06:00 UTC. Figure 15b illustrates the average of RH profiles derived from the model used for the dry LIRIC profile. Additionally, the insitu measurement and the corresponding M80 and L80 values refer to the period from 15 September at 00:00 UTC to 16 September at 00:00 UTC, 2018 (Figure 15). Similarly with the two other cases, the model results refer to the dry mass included in SSAs initially generated with radius in $0.2-10 \mu \mathrm{m}$ range at $80 \% \mathrm{RH}$ whilst lidar/sun-photometer derived volume concentrations refer to SSAs with radius in 0.439-10 $\mu \mathrm{m}$ range (Table 2). In contrast to the other two cases, in-situ measurement refers to the dry mass concentration estimated for the total suspended particles (TSP) collected under ambient RH conditions while the model concentrations used for this evaluation refer to the $0.2-10 \mu \mathrm{m}$ range at $80 \% \mathrm{RH}$. Regarding the assessment using LIRIC measurements, the M80 simulation presents an almost persistent underestimation up to $2000 \mathrm{~m}$, however, L18 presents overestimation up to $1300 \mathrm{~m}$ and underestimation from $1300 \mathrm{~m}$ to $2000 \mathrm{~m}$ (Figure 15a). L18 outperforms M80 up to $450 \mathrm{~m}$ and over $1200 \mathrm{~m}$ up to $2000 \mathrm{~m}$, however, M80 better fits with LIRIC values from $450 \mathrm{~m}$ to $1200 \mathrm{~m}$. This performance flip may be attributed to the larger lowlevel SSA concentrations of L18 which propagated higher causing overestimation, as also explained for the second case study. Overall, L18 simulation turned the underestimation of M80 to overestimation as indicated by MBE values. Moreover, L18 slightly reduced RMSE ( $1.1 \%$ reduction) as presented in Table 3 but overestimated against the in-situ measurements while M80 slightly underestimated. This may also be attributed to the increased SSA emissions of L18 even during weak winds blowing over a wide area in this case study. It is noteworthy that the gradual accumulation of SSAs in the near-sea-surface levels during the previous hours as shown by L18 20-h range reaching even $23.5 \mu \mathrm{g} \mathrm{m}^{-3}$, was reflected to the SSA concentrations at the height of the PANGEA observatory and even higher.

\section{Discussion}

SSAs are a major component of the natural aerosol mass and, thus, the modeling of their emission, concentration, circulation and impacts on the atmospheric processes demands realistic representation of air-sea interaction. Atmospheric models traditionally parameterize SSA emissions using whitecap fraction estimated by formulas dependent only on wind speed, ignoring sea state. This incomplete consideration introduces errors in the lifecycle simulation of SSAs.

In this context, this study investigates the impact of sea state on SSA modeling. Overall, despite the overestimation in some layers, the L18 simulations presented lower RMSEs in low and moderate wind speed intensities, more pronounced in the second and third case studies. This behavior is determined by specific wind and wave characteristics of each case study but is partially attributed to the validity range of L18 parameterization. This result confirms the validity of the L18 whitecap fraction parameterization for wind speeds up to $\sim 12 \mathrm{~m} \mathrm{~s}^{-1}$ as also presented by Laussac et al. [42] who used this parameterization in a revised SSA density function based on the initial studies of Monahan et al. [62], Demoisson et al. [102] and Piazzola et al. [103]. This limitation is attributed to the wind conditions which prevailed during the measurements of Laussac et al. [42], affecting the 
implementation of both the L18 whitecap fraction parameterization and the L18 revised density function. It is noteworthy that this limitation can explain part of the biases observed when comparing with the measurements in this study, highlighting the necessity of measurements during more intense wind conditions.

It is also important to note that the overestimation of L18 parameterization against lidar/sun-photometer measurements evidenced especially under low wind speeds could be eliminated using near-sea-surface SSA measurements over the central-eastern Mediterranean Sea to calibrate it for this specific area. On the other hand, evaluation against in-situ measurements did not clearly indicate which whitecap fraction parameterization resulted to the more accurate SSA concentrations, so it is difficult to draw robust conclusions.

\section{Conclusions}

This study aims to enrich SSA emission modeling with sea-state information and to assess its impact on SSA concentration in the lower atmosphere. This is based on the implementation of a new wave-age dependent parameterization (L18) for whitecap fraction in the CHAOS atmosphere-wave-chemistry coupled modeling system. CHAOS includes the WRF-ARW-Chem atmospheric-chemical model two-way coupled with the WAM wave model through the OASIS3-MCT coupler. The implementation of the L18 scheme was included in the GOCART aerosol module of WRF-ARW-Chem along with the existing M80 SSA emission scheme. The simulated SSA concentrations in the lower atmosphere were assessed for both model versions using in-situ and lidar/sun-photometer measurements at Finokalia station (Crete, Greece) on 4 and 15 July 2014 and at PANGEA observatory (Antikythera, Greece) on 15 September 2018.

The differences resulted by the application of the two parameterizations (M80 and L18) were high not only horizontally along the Mediterranean Sea but also vertically up to 2000 $\mathrm{m}$. This revealed a strong dependence of SSA emissions and concentrations on sea state. In all the three case studies that were analyzed here, young waves seem to contribute the largest part of SSAs produced by the model, even at areas characterized by weak-moderate winds. This finding is important because the wave-age dependent simulation (L18) resulted to more balanced SSA emissions across the eastern Mediterranean in comparison with the wind-speed dependent simulation (M80) that is following the high spatial variability of wind speed.

The comparison of the model outputs with lidar/sun-photometer measurements from the surface up to $2000 \mathrm{~m}$ indicated that the L18 and M80 parameterizations were characterized by significant differences in the vertical performance. Despite the L18 parameterization improved the total MBE and reduced the total RMSE per $14.2 \%, 5.6 \%$ and $1.1 \%$ in the three case studies (i.e., 4 July 2014, 15 July 2014 and 15 September 2018), respectively, it presented some discrepancies in comparison with the M80 parameterization. More specifically, the L18 parameterization offered improvements in the simulation of dry SSA mass concentrations in some layers (i.e., up to 1500 in the first case study, up to $700 \mathrm{~m}$ in the second one and up to $450 \mathrm{~m}$ as well as from 1200 to $2000 \mathrm{~m}$ in the third one) but M80 presented better fit in the rest of the layers (i.e., $1500-2000 \mathrm{~m}, 700-2000 \mathrm{~m}$ and $450-1200 \mathrm{~m}$, respectively). This discrepancy of L18 may be explained by its behavior to produce large SSA amounts over wide areas even under low wind conditions, increasing SSAs which are vertically-transported and cause overestimation in some layers.

It is noteworthy that the establishment of PANGEA lidar station provides for the first time continuous monitoring of SSA profiles in the Mediterranean allowing the continuous improvement and evaluation of model parameterizations under different meteorological conditions. This favors the development of a denser observational network. Additional sensors even including also direct SSA emission measurements along the air-sea interface could assist to adjust the model parameterizations for a wider range of meteorological and sea conditions "from the top to the bottom." Future experimental campaigns with airborne in-situ observations from aircrafts (including unmanned aerial vehicles) collocated with lidar measurements at pure marine conditions and at mixed aerosol conditions could provide an 
ideal setup for an in-depth investigation of the SSA parameterization schemes in models. Moreover, the representation of additional sea parameters such as SST and sea salinity can contribute to a more thorough SSA simulation in the atmosphere $[1,35,41,104,105]$. In this context, the recent introduction of the NEMO [59] ocean circulation model in CHAOS modeling system [49], can facilitate future improvements in the parameterization of SSA emissions including additional parameters such as SST and sea salinity.

Author Contributions: G.V., E.M., A.G. and N.S. contributed to conceptualization, formal analysis, investigation, methodology, resources, validation, visualization, writing — original draft, writingreview and editing; K.T., N.K., S.S. and A.T. contributed to conceptualization, investigation, methodology, resources, visualization, writing —original draft, writing—review and editing; M.T. and A.K. contributed to resources, visualization, writing-review and editing; C.S., V.V. and E.G., contributed to methodology, writing - review and editing; N.M., A.P., V.A. and P.K. contributed to conceptualization, methodology, resources, supervision, writing-review and editing. All authors have read and agreed to the published version of the manuscript.

Funding: V.A. and A.T. were funded by the European Research Council (grant no. 725698, D-TECT) and the European Union's Horizon 2020 research and innovation program (grand no. 654109, ACTRIS-2). E.M. was funded by a DLR VO-R young investigator group and the Deutscher Akademischer Austauschdienst (grant no. 57370121). A.K. was funded by EU H2020 E-shape project (Grant Agreement n. 820852). A.G., N.S., N.K., C.S. and N.M. were funded by the project "PANhellenic infrastructure for Atmospheric Composition and climatE change" (MIS 5021516), which is implemented under the Action "Reinforcement of the Research and Innovation Infrastructure," funded by the Operational Programme "Competitiveness, Entrepreneurship and Innovation" (NSRF 2014-2020) and co-financed by Greece and the European Union (European Regional Development Fund). NOA team acknowledges support by the Stavros Niarchos Foundation, the General Secretariat for Research and Technology and the Hellenic Foundation for Research and Innovation (grant no. 294).

Institutional Review Board Statement: Not applicable.

Informed Consent Statement: Not applicable.

Data Availability Statement: The GFS-ANL data of the NCEP presented in this study are publicly available at: https://www.ncdc.noaa.gov/data-access/model-data/model-datasets/global-forcastsystem-gfs. The sun-photometer data used in this work are publicly available at the AERONET website: https:/ / aeronet.gsfc.nasa.gov/. The Polly ${ }^{\mathrm{XT}}$ lidar data and the lidar-CHAOS model evaluation datasets presented in this study can be accessed through the REACT database (Varlas et al., 2021). The FLEXPART-WRF data, the in-situ measurements, and the rest of the CHAOS model data presented in this study are available on request from the corresponding author (G.V.). G.V.; E.M.; A.G.; N.S.; K.T.; N.K.; S.S.; A.T.; C.S.; M.T.; A.K.; V.V.; E.G.; A.A.; N.M.; A.P.; P.K.: available at: https://react.space.noa.gr/papers/Varlas_et_al_2021/Dataset/, last access: 8 February 2021.

Acknowledgments: The National Center for Environmental Prediction (NCEP) is gratefully acknowledged for the kind provision of the Global Forecasting System operational analyses (GFS-ANL) and the real time global (RTG) sea surface temperature (SST) analyses used in the simulations performed in this study. The Atmosphere and Climate Dynamics Group, Geography Department, Harokopio University of Athens is fruitfully acknowledged for the computational resources used for the numerical simulations of this study. The National Observatory of Athens (NOA) is also acknowledged for the kind provision of meteorological observations at Agios Nikolaos and Falasarna stations. We thank EARLINET (https:/ / www.earlinet.org/, last access: 17 December 2020), ACTRIS (https:/ /www.actris.eu, last access: 17 December 2020), AERONET (https:/ /aeronet.gsfc.nasa.gov/, last access: 17 December 2020) and AERONET-Europe for the data collection, calibration, processing and dissemination. The European Organization for the Exploitation of Meteorological Satellites (EUMETSAT) and the website: https:/ / weather.us/satellite/greece/satellite-visible-archive/are also acknowledged for the provision and illustration, respectively, of satellite data used for the identification of cloudiness. We thank the PollyNet group (polly.tropos.de) for their support during the development and operation of the Polly ${ }^{x \mathrm{~T}}$ lidar of NOA and OCEANET. We thank European Space Agency (esa.int) for funding the CHARADMExp campaign. This research was supported by data and services obtained from the PANhellenic Geophysical Observatory of Antikythera (PANGEA) of NOA.

Conflicts of Interest: The authors declare no conflict of interest. 


\section{References}

1. Leeuw, D.G.; Andreas, E.L.; Anguelova, M.D.; Fairall, C.W.; Lewis, E.R.; O’Dowd, C.; Schulz, M.; Schwartz, S.E. Production flux of sea spray aerosol. Rev. Geophys. 2011, 49. [CrossRef]

2. Ma, X.; Salzen, K.V.; Li, J. Modelling sea salt aerosol and its direct and indirect effects on climate. Atmos. Chem. Phys. 2008, 8, 1311-1327. [CrossRef]

3. Lewis, E.; Schwartz, S. Sea Salt Aerosol Production: Mechanisms, Methods, Measurements and Models-A Critical Review. Am. Geophys. Union Geophys. Monogr. Ser. 2004, 152, 3719.

4. Spiel, D.E. On the births of jet drops from bubbles bursting on water surfaces. J. Geophys. Res. Ocean. 1995, 100, 4995-5006. [CrossRef]

5. Andreas, E.L. A review of the sea spray generation function for the open ocean. Adv. Fluid Mech. 2002, 33, 1-46.

6. Blanchard, D.C. The production, distribution, and bacterial enrichment of the sea-salt aerosol. In Air-Sea Exchange of Gases and Particles; Springer: New York, NY, USA, 1983; pp. 407-454.

7. $\mathrm{Wu}, \mathrm{J}$. Production of spume drops by the wind tearing of wave crests: The search for quantification. J. Geophys. Res. $1993,98,8221$. [CrossRef]

8. Andreas, E.L.; Edson, J.B.; Monahan, E.C.; Rouault, M.P.; Smith, S.D. The spray contribution to net evaporation from the sea: A review of recent progress. Bound. Layer Meteorol. 1995, 72, 3-52. [CrossRef]

9. Rizza, U.; Canepa, E.; Miglietta, M.M.; Passerini, G.; Morichetti, M.; Mancinelli, E.; Virgili, S.; Besio, G.; Leo, D.F.; Mazzino, A. Evaluation of drag coefficients under medicane conditions: Coupling waves, sea spray and surface friction. Atmos. Res. 2021, 247, 5207. [CrossRef]

10. Lundgren, K.; Vogel, B.; Vogel, H.; Kottmeier, C. Direct radiative effects of sea salt for the Mediterranean region under conditions of low to moderate wind speeds. J. Geophys. Res. Atmos. 2013, 118, 1906-1923. [CrossRef]

11. Nazarenko, L.; Rind, D.; Tsigaridis, K.; Genio, D.A.D.; Kelley, M.; Tausnev, N. Interactive nature of climate change and aerosol forcing. J. Geophys. Res. Atmos. 2017, 122, 3457-3480. [CrossRef] [PubMed]

12. Bender, F.M.; Frey, L.; McCoy, D.T.; Grosvenor, D.P.; Mohrmann, J.K. Assessment of aerosol-cloud-radiation correlations in satellite observations, climate models and reanalysis. Clim. Dyn. 2019, 52, 4371-4392. [CrossRef]

13. Bi, L.; Lin, W.; Wang, Z.; Tang, X.; Zhang, X.; Yi, B. Optical modeling of sea salt aerosols: The effects of nonsphericity and inhomogeneity. J. Geophys. Res. Atmos. 2018, 123, 543-558. [CrossRef]

14. Quinn, P.K.; Coffman, D.J.; Johnson, J.E.; Upchurch, L.M.; Bates, T.S. Small fraction of marine cloud condensation nuclei made up of sea spray aerosol. Nat. Geosci. 2017, 10, 674-679. [CrossRef]

15. Wilson, T.W.; Ladino, L.A.; Alpert, P.A.; Breckels, M.N.; Brooks, I.M.; Browse, J.; Burrows, S.M.; Carslaw, K.S.; Huffman, J.A.; Judd, C. A marine biogenic source of atmospheric ice-nucleating particles. Nature 2015, 525, 234-238. [CrossRef]

16. Solomos, S.; Kallos, G.; Kushta, J.; Astitha, M.; Tremback, C.; Nenes, A.; Levin, Z. An integrated modeling study on the effects of mineral dust and sea salt particles on clouds and precipitation. Atmos. Chem. Phys. 2011, 11, 873-892. [CrossRef]

17. Horowitz, H.M.; Holmes, C.; Wright, A.; Sherwen, T.; Wang, X.; Evans, M.; Huang, J.; Jaeglé, L.; Chen, Q.; Zhai, S. Effects of sea salt aerosol emissions for Marine Cloud Brightening on atmospheric chemistry: Implications for radiative forcing. Geophys. Res. Lett. 2020, 47, 5838. [CrossRef] [PubMed]

18. Levin, Z.; Teller, A.; Ganor, E.; Yin, Y. On the interactions of mineral dust, sea-salt particles, and clouds: A measurement and modeling study from the Mediterranean Israeli Dust Experiment campaign. J. Geophys. Res. Atmos. 2005, 110. [CrossRef]

19. Mårtensson, M.; Tunved, P.; Korhonen, H.; Nilsson, D. The role of sea-salt emissions in controlling the marine Aitken and accumulation mode aerosol: A model study. Tellus B Chem. Phys. Meteorol. 2010, 62, 259-279. [CrossRef]

20. Jiang, B.; Wang, D.; Shen, X.; Chen, J.; Lin, W. Effects of sea salt aerosols on precipitation and upper troposphere/lower stratosphere water vapour in tropical cyclone systems. Sci. Rep. 2019, 9, 15105. [CrossRef]

21. Blanchard, D.C. The electrification of the atmosphere by particles from bubbles in the sea. Prog. Oceanogr. 1963, 1, 73-202. [CrossRef]

22. Piazzola, J.; Mihalopoulos, N.; Canepa, E.; Tedeschi, G.; Prati, P.; Zarmpas, P.; Bastianini, M.; Missamou, T.; Cavaleri, L. Characterization of aerosols above the Northern Adriatic Sea: Case studies of offshore and onshore wind conditions. Atmos. Environ. 2016, 132, 153-162. [CrossRef]

23. Seinfeld, J.H.; Pandis, S.N. Atmospheric Chemistry and Physics: From Air Pollution to Climate Change; John Wiley \& Sons: New York, NY, USA, 2016; ISBN 1118947401.

24. Athanasopoulou, E.; Tombrou, M.; Pandis, S.N.; Russell, A.G. The role of sea-salt emissions and heterogeneous chemistry in the air quality of polluted coastal areas. Atmos. Chem. Phys. 2008, 8, 5755-5769. [CrossRef]

25. Cochran, R.E.; Ryder, O.S.; Grassian, V.H.; Prather, K.A. Sea spray aerosol: The chemical link between the oceans, atmosphere, and climate. Acc. Chem. Res. 2017, 50, 599-604. [CrossRef]

26. O'Dowd, C.D.; Langmann, B.; Varghese, S.; Scannell, C.; Ceburnis, D.; Facchini, M.C. A combined organic-inorganic sea-spray source function. Geophys. Res. Lett. 2008, 35. [CrossRef]

27. Vignati, E.; Facchini, M.C.; Rinaldi, M.; Scannell, C.; Ceburnis, D.; Sciare, J.; Kanakidou, M.; Myriokefalitakis, S.; Dentener, F.; O'Dowd, C.D. Global scale emission and distribution of sea-spray aerosol: Sea-salt and organic enrichment. Atmos. Environ. 2010, 44, 670-677. [CrossRef] 
28. Quinn, P.K.; Bates, T.S.; Schulz, K.S.; Coffman, D.J.; Frossard, A.A.; Russell, L.M.; Keene, W.C.; Kieber, D.J. Contribution of sea surface carbon pool to organic matter enrichment in sea spray aerosol. Nat. Geosci. 2014, 7, 228-232. [CrossRef]

29. Ciuraru, R.; Fine, L.; Pinxteren, V.M.; D’Anna, B.; Herrmann, H.; George, C. Photosensitized production of functionalized and unsaturated organic compounds at the air-sea interface. Sci. Rep. 2015, 5, 2741. [CrossRef] [PubMed]

30. Ehrenhauser, F.S.; Avij, P.; Shu, X.; Dugas, V.; Woodson, I.; Arachchi, L.T.; Zhang, Z.; Hung, F.R.; Valsaraj, K.T. Bubble bursting as an aerosol generation mechanism during an oil spill in the deep-sea environment: Laboratory experimental demonstration of the transport pathway. Environ. Sci. Process. Impacts 2014, 16, 65-73. [CrossRef]

31. Mohajer, A.N.; Fox, M.A.; Koehler, K. The human health risk estimation of inhaled oil spill emissions with and without adding dispersant. Sci. Total Environ. 2019, 654, 924-932. [CrossRef]

32. Monahan, E.C.; Muircheartaigh, I. Optimal power-law description of oceanic whitecap coverage dependence on wind speed. J. Phys. Oceanogr. 1980, 10, 2094-2099. [CrossRef]

33. Anguelova, M.D.; Webster, F. Whitecap coverage from satellite measurements: A first step toward modeling the variability of oceanic whitecaps. J. Geophys. Res. Ocean. 2006, 111. [CrossRef]

34. Tsyro, S.; Aas, W.; Soares, J.; Sofiev, M.; Berge, H.; Spindler, G. Modelling of sea salt concentrations over Europe: Key uncertainties and comparison with observations. Atmos. Chem. Phys. 2011, 11, 10367-10388. [CrossRef]

35. Mårtensson, E.M.; Nilsson, E.D.; Leeuw, D.G.; Cohen, L.H.; Hansson, H. Laboratory simulations and parameterization of the primary marine aerosol production. J. Geophys. Res. Atmos. 2003, 108. [CrossRef]

36. Clarke, A.D.; Owens, S.R.; Zhou, J. An ultrafine sea-salt flux from breaking waves: Implications for cloud condensation nuclei in the remote marine atmosphere. J. Geophys. Res. Atmos. 2006, 111. [CrossRef]

37. Lafon, C.; Piazzola, J.; Forget, P.; Calve, L.O.; Despiau, S. Analysis of the variations of the whitecap fraction as measured in a coastal zone. Bound. Layer Meteorol. 2004, 111, 339-360. [CrossRef]

38. Lafon, C.; Piazzola, J.; Forget, P.; Despiau, S. Whitecap coverage in coastal environment for steady and unsteady wave field conditions. J. Mar. Syst. 2007, 66, 38-46. [CrossRef]

39. Shi, J.; Zhao, D.; Li, X.Q.; Zhong, Z. New wave-dependent formulae for sea spray flux at air-sea interface. J. Hydrodyn. 2009, 21, 573-581. [CrossRef]

40. Piazzola, J.; Forget, P.; Lafon, C.; Despiau, S. Spatial variation of sea-spray fluxes over a Mediterranean coastal zone using a sea-state model. Bound. Layer Meteorol. 2009, 132, 167-183. [CrossRef]

41. Albert, M.F.M.A.; Anguelova, M.D.; Manders, A.M.M.; Schaap, M.; Leeuw, D.G. Parameterization of oceanic whitecap fraction based on satellite observations. Atmos. Chem. Phys. 2016, 16, 13725-13751. [CrossRef]

42. Laussac, S.; Piazzola, J.; Tedeschi, G.; Yohia, C.; Canepa, E.; Rizza, U.; Eijk, V.A.M.J. Development of a fetch dependent sea-spray source function using aerosol concentration measurements in the North-Western Mediterranean. Atmos. Environ. 2018, 193, 177-189. [CrossRef]

43. Ovadnevaite, J.; Manders, A.; Leeuw, D.G.; Ceburnis, D.; Monahan, C.; Partanen, A.I.; Korhonen, H.; O’Dowd, C.D. A sea spray aerosol flux parameterization encapsulating wave state. Atmos. Chem. Phys. 2014, 14, 1837-1852. [CrossRef]

44. Varlas, G. Development of an Integrated Modeling System for Simulating the Air-Ocean Wave Interactions. Ph.D. Dissertation, Harokopio University of Athens (HUA), Athens, Greece, 2017. Available online: https:/ /www.didaktorika.gr/eadd/handle/10 442/41238 (accessed on 17 December 2020).

45. Varlas, G.; Katsafados, P.; Papadopoulos, A.; Korres, G. Implementation of a two-way coupled atmosphere-ocean wave modeling system for assessing air-sea interaction over the Mediterranean Sea. Atmos. Res. 2018, 208, 201-217. [CrossRef]

46. Katsafados, P.; Varlas, G.; Papadopoulos, A.; Spyrou, C.; Korres, G. Assessing the Implicit Rain Impact on Sea State During Hurricane Sandy (2012). Geophys. Res. Lett. 2018, 45, 12015-12022. [CrossRef]

47. Varlas, G.; Anagnostou, M.N.; Spyrou, C.; Papadopoulos, A.; Kalogiros, J.; Mentzafou, A.; Michaelides, S.; Baltas, E.; Karymbalis, E.; Katsafados, P. A multi-platform hydrometeorological analysis of the flash flood event of 15 November 2017 in Attica, Greece. Remote Sens. 2019, 11, 45. [CrossRef]

48. Varlas, G.; Spyrou, C.; Papadopoulos, A.; Korres, G.; Katsafados, P. One-year assessment of the CHAOS two-way coupled atmosphere-ocean wave modelling system over the Mediterranean and Black Seas. Mediterr. Mar. Sci. 2020, $21,372-385$.

49. Varlas, G.; Vervatis, V.; Spyrou, C.; Papadopoulou, E.; Papadopoulos, A.; Katsafados, P. Investigating the impact of atmospherewave-ocean interactions on a Mediterranean tropical-like cyclone. Ocean. Model. 2020, 153. [CrossRef]

50. Skamarock, W.C.; Klemp, J.B.; Dudhia, J.; Gill, D.O.; Zhiquan, L.; Berner, J.; Wang, W.; Powers, J.G.; Duda, M.G.; Barker, D.M.; et al. A Description of the Advanced Research WRF Model Version 4. Natl. Cent. Atmos. Res. 2019, 145. [CrossRef]

51. Grell, G.A.; Peckham, S.E.; Schmitz, R.; McKeen, S.A.; Frost, G.; Skamarock, W.C.; Eder, B. Fully coupled "online" chemistry within the WRF model. Atmos. Environ. 2005, 39, 6957-6975. [CrossRef]

52. Günther, H.; Behrens, A. The WAM Model-Validation Document, Version 4.5.4; Institute of Coastal Research Helmholtz-Zentrum Geesthacht: Geesthacht, Germany, 2012; p. 92.

53. Komen, G.J.; Cavaleri, L.; Donelan, M.; Hasselmann, K.; Hasselmann, S.; Janssen, P.A.E.M. Dynamics and Modelling of Ocean. Waves; Cambridge University Press: Cambridge, UK, 1994; ISBN 9780521577816.

54. Group, T.W. The WAM model-A third generation ocean wave prediction model. J. Phys. Oceanogr. 1988, 18, 1775-1810. [CrossRef]

55. Valcke, S.; Craig, T.; Coquart, L. OASIS3-MCT_3. 0 Coupler User Guide; CERFACS: Toulouse, France, 2015. 
56. Craig, A.; Valcke, S.; Coquart, L. Development and performance of a new version of the OASIS coupler, OASIS3-MCT_3. 0. Geosci. Model. Dev. 2017, 10, 3297-3308. [CrossRef]

57. Gochis, D.J.; Barlage, M.; Dugger, A.; Fitzgerald, K.; Karsten, L.; Mcallister, M.; Mccreight, J.; Mills, J.; Rafieeinasab, A.; Read, L.; et al. WRF-Hydro Technical Description, (version 5.0). NCAR Tech. Note 2018, 107. [CrossRef]

58. Katsafados, P.; Papadopoulos, A.; Korres, G.; Varlas, G. A fully coupled atmosphere-ocean wave modeling system for the Mediterranean Sea: Interactions and sensitivity to the resolved scales and mechanisms. Geosci. Model. Dev. 2016, 9, 161-173. [CrossRef]

59. Madec, G. The NEMO team, 2012: NEMO ocean engine. Note Modélisation 2017. [CrossRef]

60. Chin, M.; Rood, R.B.; Lin, S.J.; Müller, J.F.; Thompson, A.M. Atmospheric sulfur cycle simulated in the global model GOCART: Model description and global properties. J. Geophys. Res. Atmos. 2000, 105, 24671-24687. [CrossRef]

61. Chin, M.; Ginoux, P.; Kinne, S.; Torres, O.; Holben, B.N.; Duncan, B.N.; Martin, R.V.; Logan, J.A.; Higurashi, A.; Nakajima, T. Tropospheric aerosol optical thickness from the GOCART model and comparisons with satellite and Sun photometer measurements. J. Atmos. Sci. 2002, 59, 461-483. [CrossRef]

62. Monahan, E.C.; Spiel, D.E.; Davidson, K.L. A model of marine aerosol generation via whitecaps and wave disruption. In Oceanic Whitecaps; Springer: New York, NY, USA, 1986; pp. 167-174.

63. Gong, S.L.; Barrie, L.A.; Blanchet, J.P. Modeling sea-salt aerosols in the atmosphere 1. Model development. J. Geophys. Res. Atmos. 1997, 102, 3805-3818. [CrossRef]

64. Jia, N.; Zhao, D. The Influence of Wind Speed and Sea States on Whitecap Coverage. J. Ocean. Univ. China 2019, 18, 282-292. [CrossRef]

65. Danielson, J.J.; Gesch, D.B. Global Multi-Resolution Terrain Elevation Data 2010 (GMTED2010); US Department of the Interior, US Geological Survey: Washington, DC, USA, 2011.

66. Jiménez, P.A.; Dudhia, J.; Rouco, G.J.F.; Navarro, J.; Montávez, J.P.; Bustamante, G.E. A revised scheme for the WRF surface layer formulation. Mon. Weather Rev. 2012, 140, 898-918. [CrossRef]

67. Hong, S.Y.; Noh, Y.; Dudhia, J. A new vertical diffusion package with an explicit treatment of entrainment processes. Mon. Weather Rev. 2006, 134, 2318-2341. [CrossRef]

68. Tewari, M.N.; Tewari, M.; Chen, F.; Wang, W.; Dudhia, J.; Mone, L.M.; Mitchell, K.; Ek, M.; Gayno, G.; Wegiel, J. Implementation and verification of the unified NOAH land surface model in the WRF model (Formerly Paper Number 17.5). In Proceedings of the 20th Conference on Weather Analysis and Forecasting/16th Conference on Numerical Weather Prediction, Seattle, WA, USA, 14 January 2004; pp. 11-15.

69. Iacono, M.J.; Delamere, J.S.; Mlawer, E.J.; Shephard, M.W.; Clough, S.A.; Collins, W.D. Radiative forcing by long-lived greenhouse gases: Calculations with the AER radiative transfer models. J. Geophys. Res. Atmos. 2008, 113, 2-9. [CrossRef]

70. Thompson, G.; Field, P.R.; Rasmussen, R.M.; Hall, W.D. Explicit forecasts of winter precipitation using an improved bulk microphysics scheme. Part II: Implementation of a new snow parameterization. Mon. Weather Rev. 2008, 136, 5095-5115. [CrossRef]

71. Grell, G.A.; Freitas, S.R. A scale and aerosol aware stochastic convective parameterization for weather and air quality modeling. Atmos. Chem. Phys. 2014, 14, 5233-5250. [CrossRef]

72. Amante, C.; Eakins, B.W. ETOPO1 Arc-Minute Global Relief Model: Procedures, Data Sources and Analysis; National Geophysical Data Center: Boulder, CO, USA, 2009.

73. Fairall, C.W.; Bradley, E.F.; Hare, J.E.; Grachev, A.A.; Edson, J.B. Bulk parameterization of air-sea fluxes: Updates and verification for the COARE algorithm. J. Clim. 2003, 16, 571-591. [CrossRef]

74. Janssen, P. The Interaction of Ocean. Waves and Wind; Cambridge University Press: Cambridge, UK, 2004 ; ISBN 9780521465403.

75. Janssen, P. Wave-Induced Stress and the Drag of Air Flow over Sea Waves. J. Phys. Oceanogr. 1989, 19, 745-754. [CrossRef]

76. Janssen, P. Quasi-linear Theory of Wind-Wave Generation Applied to Wave Forecasting. J. Phys. Oceanogr. 1991, 21, 1631-1642. [CrossRef]

77. Mihalopoulos, N.; Stephanou, E.; Kanakidou, M.; Pilitsidis, S.; Bousquet, P. Tropospheric aerosol ionic composition in the Eastern Mediterranean region. Tellus B 1997, 49, 314-326. [CrossRef]

78. Lelieveld, J.; Berresheim, H.; Borrmann, S.; Crutzen, P.J.; Dentener, F.J.; Fischer, H.; Feichter, J.; Flatau, P.J.; Heland, J.; Holzinger, R. Global air pollution crossroads over the Mediterranean. Science 2002, 298, 794-799. [CrossRef] [PubMed]

79. Engelmann, R.; Kanitz, T.; Baars, H.; Heese, B.; Althausen, D.; Skupin, A.; Wandinger, U.; Komppula, M.; Stachlewska, I.S.; Amiridis, V. The automated multiwavelength Raman polarization and water-vapor lidar Polly ${ }^{\mathrm{XT}}$ : The neXT generation. Atmos. Meas. Tech. 2016, 9, 1767-1784. [CrossRef]

80. Pappalardo, G.; Amodeo, A.; Apituley, A.; Comeron, A.; Freudenthaler, V.; Linné, H.; Ansmann, A.; Bösenberg, J.; D’Amico, G.; Mattis, I. EARLINET. Atmos. Meas. Tech. 2014, 7, 2389-2409. [CrossRef]

81. Baars, H.; Kanitz, T.; Engelmann, R.; Althausen, D.; Heese, B.; Komppula, M.; Preißler, J.; Tesche, M.; Ansmann, A.; Wandinger, U. An overview of the first decade of PollyNET: An emerging network of automated Raman-polarization lidars for continuous aerosol profiling. Atmos. Chem. Phys. 2016, 16, 5111-5137. [CrossRef]

82. Fernald, F.G.; Herman, B.M.; Reagan, J.A. Determination of aerosol height distributions by lidar. J. Appl. Meteorol. 1972, 11, 482-489. [CrossRef]

83. Fernald, F.G. Analysis of atmospheric lidar observations: Some comments. Appl. Opt. 1984, 23, 652-653. [CrossRef] [PubMed] 
84. Klett, J.D. Stable analytical inversion solution for processing lidar returns. Appl. Opt. 1981, 20, 211-220. [CrossRef] [PubMed]

85. Klett, J.D. Lidar inversion with variable backscatter/extinction ratios. Appl. Opt. 1985, 24, 1638-1643. [CrossRef]

86. Ansmann, A.; Wandinger, U.; Riebesell, M.; Weitkamp, C.; Michaelis, W. Independent measurement of extinction and backscatter profiles in cirrus clouds by using a combined Raman elastic-backscatter lidar. Appl. Opt. 1992, 31, 7113-7131. [CrossRef]

87. Freudenthaler, V.; Esselborn, M.; Wiegner, M.; Heese, B.; Tesche, M.; Ansmann, A.; Müller, D.; Althausen, D.; Wirth, M.; Fix, A. Depolarization ratio profiling at several wavelengths in pure Saharan dust during SAMUM 2006. Tellus B Chem. Phys. Meteorol. 2009, 61, 165-179. [CrossRef]

88. Dai, G.; Althausen, D.; Hofer, J.; Engelmann, R.; Seifert, P.; Bühl, J.; Mamouri, R.E.; Wu, S.; Ansmann, A. Calibration of Raman lidar water vapor profiles by means of AERONET photometer observations and GDAS meteorological data. Atmos. Meas. Tech. 2018, 11, 2735-2748. [CrossRef]

89. Chaikovsky, A.; Dubovik, O.; Holben, B.; Bril, A.; Goloub, P.; Tanré, D.; Pappalardo, G.; Wandinger, U.; Chaikovskaya, L.; Denisov, $\mathrm{S}$. Lidar-Radiometer Inversion Code (LIRIC) for the retrieval of vertical aerosol properties from combined lidar/radiometer data: Development and distribution in EARLINET. Atmos. Meas. Tech. 2016, 9, 1181-1205. [CrossRef]

90. Tsekeri, A.; Lopatin, A.; Amiridis, V.; Marinou, E.; Igloffstein, J.; Siomos, N.; Solomos, S.; Kokkalis, P.; Engelmann, R.; Baars, H. GARRLiC and LIRIC: Strengths and limitations for the characterization of dust and marine particles along with their mixtures. Atmos. Meas. Tech. 2017, 10, 4995-5016. [CrossRef]

91. Kokkalis, P.; Amiridis, V.; Allan, J.D.; Papayannis, A.; Solomos, S.; Binietoglou, I.; Bougiatioti, A.; Tsekeri, A.; Nenes, A.; Rosenberg, P.D. Validation of LIRIC aerosol concentration retrievals using airborne measurements during a biomass burning episode over Athens. Atmos. Res. 2017, 183, 255-267. [CrossRef]

92. Binietoglou, I.; Basart, S.; Arboledas, A.L.; Amiridis, V.; Argyrouli, A.; Baars, H.; Baldasano, J.M.; Balis, D.; Belegante, L.; Aranda, B.J.A. A methodology for investigating dust model performance using synergistic EARLINET/AERONET dust concentration retrievals. Atmos. Meas. Tech. 2015, 8, 3577-3600. [CrossRef]

93. Siomos, N.; Balis, D.S.; Poupkou, A.; Liora, N.; Spyridon, D.; Melas, D.; Giannakaki, E.; Filioglou, M.; Basart, S.; Chaikovsky, A. Investigating the quality of modeled aerosol profiles based on combined lidar and sunphotometer data. Atmos. Chem. Phys. 2017, 17, 7003-7023. [CrossRef]

94. Tsekeri, A.; Amiridis, V.; Kokkalis, P.; Alpuente, B.S.; Chaikovsky, A.; Dubovik, O.; Mamouri, R.E.; Papayannis, A.; Baldasano Recio, J.M. Application of a synergetic lidar and sunphotometer algorithm for the characterization of a dust event over Athens, Greece. Br. J. Environ. Clim. Chang. 2013, 3, 531-546. [CrossRef] [PubMed]

95. Tsekeri, A.; Amiridis, V.; Marenco, F.; Nenes, A.; Marinou, E.; Solomos, S.; Rosenberg, P.; Trembath, J.; Nott, G.J.; Allan, J. Profiling aerosol optical, microphysical and hygroscopic properties in ambient conditions by combining in situ and remote sensing. Atmos. Meas. Tech. 2017, 10, 83-107. [CrossRef]

96. Paraskevopoulou, D.; Liakakou, E.; Gerasopoulos, E.; Theodosi, C.; Mihalopoulos, N. Long-term characterization of organic and elemental carbon in the PM 2.5 fraction: The case of Athens, Greece. Atmos. Chem. Phys. 2014, 14, 13313-13325. [CrossRef]

97. Sciare, J.; Oikonomou, K.; Cachier, H.; Mihalopoulos, N.; Andreae, M.O.; Maenhaut, W.; Estève, S.R. Aerosol mass closure and reconstruction of the light scattering coefficient over the Eastern Mediterranean Sea during the MINOS campaign. Atmos. Chem. Phys. 2005, 5, 2253-2265. [CrossRef]

98. Brioude, J.; Arnold, D.; Stohl, A.; Cassiani, M.; Morton, D.; Seibert, P.; Angevine, W.; Evan, S.; Dingwell, A.; Fast, J.D. The Lagrangian particle dispersion model FLEXPART-WRF version 3.1. Geosci. Model. Dev. 2013, 6, 1889-1904. [CrossRef]

99. Haarig, M.; Ansmann, A.; Gasteiger, J.; Kandler, K.; Althausen, D.; Baars, H.; Radenz, M.; Farrell, D.A. Dry versus wet marine particle optical properties: RH dependence of depolarization ratio, backscatter, and extinction from multiwavelength lidar measurements during SALTRACE. Atmos. Chem. Phys. 2017, 17, 4199. [CrossRef]

100. De Leeuw, G.; Neele, F.P.; Hill, M.; Smith, M.H.; Vignati, E. Production of sea spray aerosol in the surf zone. J. Geophys. Res. Atmos. 2000, 105, 29397-29409. [CrossRef]

101. Papadopoulos, A.; Varlas, G. Weather Systems Affecting the Meteorological Conditions over the Aegean Sea. In The Handbook of Environmental Chemistry; Springer: Berlin/Heidelberg, Germany, 2020. [CrossRef]

102. Demoisson, A.; Tedeschi, G.; Piazzola, J. A model for the atmospheric transport of sea-salt particles in coastal areas. Atmos. Res. 2013, 132, 144-153. [CrossRef]

103. Piazzola, J.; Bouchara, F.; Leeuw, G.; Eijk, V.A.M.J. Development of the Mediterranean extinction code (MEDEX). Opt. Eng. 2003, 42, 912-924. [CrossRef]

104. Jaeglé, L.; Quinn, P.K.; Bates, T.S.; Alexander, B.; Lin, J.T. Global distribution of sea salt aerosols: New constraints from in situ and remote sensing observations. Atmos. Chem. Phys. 2011, 11, 3137. [CrossRef]

105. Spada, M.; Jorba, O.; Pando, P.G.C.; Janjic, Z.; Baldasano, J.M. Modeling and evaluation of the global sea-salt aerosol distribution: Sensitivity to size-resolved and sea-surface temperature dependent emission schemes. Atmos. Chem. Phys. 2013, 13, 11735-11755. [CrossRef] 